\title{
Comparative transcriptome analysis of the invasive weed Mikania micrantha with its native congeners provides insights into genetic basis underlying successful invasion
}

Wuxia Guo', Ying Liu', Wei Lun Ng${ }^{1}$, Pei-Chun Liao², Bing-Hong Huang ${ }^{2}$, Weixi Li', Chunmei Li', Xianggang Shi $^{1}$ and Yelin Huang ${ }^{1 *}$ (D)

\begin{abstract}
Background: Mikania micrantha H.B.K. (Asteraceae) is one of the world's most invasive weeds which has been rapidly expanding in tropical Asia, including China, while its close relative M. cordata, the only Mikania species native to China, shows no harm to the local ecosystems. These two species are very similar in morphology but differ remarkably in several ecological and physiological traits, representing an ideal system for comparative analysis to investigate the genetic basis underlying invasion success. In this study, we performed RNA-sequencing on the invader M. micrantha and its native congener M. cordata in China, to unravel the genetic basis underlying the strong invasiveness of $M$. micrantha. For a more robust comparison, another non-invasive congener $M$. cordifolia was also sequenced and compared.

Results: A total of 52,179,55,835, and 52,983 unigenes were obtained for M. micrantha, M. cordata, and M. cordifolia, respectively. Phylogenetic analyses and divergence time dating revealed a relatively recent split between $M$. micrantha and M. cordata, i.e., approximately 4.81 million years ago (MYA), after their divergence with M. cordifolia (8.70 MYA). Gene ontology classifications, pathway assignments and differential expression analysis revealed higher representation or significant up-regulation of genes associated with photosynthesis, energy metabolism, protein modification and stress response in M. micrantha than in M. cordata or M. cordifolia. Analysis of accelerated evolution and positive selection also suggested the importance of these related genes and processes to the adaptability and invasiveness of M. micrantha. Particularly, most (77 out of 112, i.e. 68.75\%) positively selected genes found in M. micrantha could be classified into four groups, i.e., energy acquisition and utilization (10 genes), growth and reproduction (13 genes), protection and repair (34 genes), and signal transduction and expression regulation (20 genes), which may have contributed to the high adaptability of $M$. micrantha to various new environments and the capability to occupy a wider niche, reflected in its high invasiveness.
\end{abstract}

Conclusions: We characterized the transcriptomes of the invasive species M. micrantha and its non-invasive congeners, M. cordata and M. cordifolia. A comparison of their transcriptomes provided insights into the genetic basis of the high invasiveness of M. micrantha.

Keywords: Invasion, Eco-adaptation, Positive selection, Comparative transcriptomics, Mikania

\footnotetext{
* Correspondence: Isshy|@mail.sysu.edu.cn

'State Key Laboratory of Biocontrol and Guangdong Provincial Key

Laboratory of Plant Resources, School of Life Sciences, Sun Yat-sen University,

135 Xingang West Road, 510275 Guangzhou, Guangdong, People's Republic

of China

Full list of author information is available at the end of the article
}

(c) The Author(s). 2018 Open Access This article is distributed under the terms of the Creative Commons Attribution 4.0 International License (http://creativecommons.org/licenses/by/4.0/), which permits unrestricted use, distribution, and reproduction in any medium, provided you give appropriate credit to the original author(s) and the source, provide a link to the Creative Commons license, and indicate if changes were made. The Creative Commons Public Domain Dedication waiver (http://creativecommons.org/publicdomain/zero/1.0/) applies to the data made available in this article, unless otherwise stated. 


\section{Background}

When a species is introduced into a new environment, it either does not adapt and quickly goes extinct or persists and establishes in the new environment. Species that live on may become competitive and colonize new areas and niches at high rates, eventually becoming successful invaders. Since many invasive species pose serious threat to native biodiversity and cause severe economic loss in the affected regions [1-5], biological invasion has long been recognized as a leading threat to the functioning of local ecosystems and global biodiversity $[6,7]$. As transmission of biological material increases worldwide due to the development of international trade and more frequent human activity $[5,8]$, such crisis becomes increasingly severe. Understanding the mechanisms by which invasive plants succeed would eventually be useful for control efforts [9] and thus are of great importance and necessity. Over the past decades, extensive insights have been gained on the biology or ecology of plant invasion, which suggests several factors to be responsible for invasive success, including external environmental conditions (e.g., lack of natural enemies, increased anthropogenic disturbance, and a wide range of invasive habitats) and their intrinsic biological characteristics (e.g., the capability of rapid reproduction, broad eco-adaptability, and strong allelopathic effects) [10-15]. However, the relative lack of genomic data for invasive plants, which represent mostly non-model species, hinders research on this group of organisms at the molecular level. As the development of transcriptome sequencing technology offers a convenient and efficient means to obtain genome resources in non-model species [16-18], it provides an opportunity for comparative study of closely related invasive and non-invasive congeners, as an effective approach to identify the genetic basis and mechanisms of invasive success $[9,19,20]$.

Mikania micrantha H.B.K. is a perennial vine that belongs to the family Asteraceae. This species is native to tropical America, and has been recognized as one of the world's most notorious invaders [9, 21]. With its extremely fast growth and ability of both sexual and asexual reproduction, $M$. micrantha can rapidly colonize disturbed habitats, while competing with the native vegetation and retarding their growth [5, 22-24]. Due to both external (e.g., human activity) and internal (e.g., strong invasiveness) reasons, the plant is now widely distributed across tropical Asia and the Pacific Islands, causing serious economic and environmental impacts [5, 13, 21, 25-29]. Among the more than 400 Mikania species, most of which native to tropical America, M. micrantha is the only species that has spread from the New World to the Old World, and now coexists with its native congener in the Old World, $M$. cordata (Burm. f.) B. L. Robinson [30-33]. The earliest record of $M$. micrantha in the Old World could be traced back to
1884 in Hong Kong, and after then, M. micrantha has expanded in southern China, covering Hong Kong and the Guangdong and Taiwan provinces [33]. In contrast, M. cordata is the only Mikania species native in South China, distributed in Yunnan, Hainan, and Taiwan provinces [13, 34, 35]. Interestingly, although $M$. micrantha and $M$. cordata appear to be quite similar to each other in morphology and life style, they show considerable differences in many ecological traits, such as niche requirements, eco-adaptability, and most importantly, invasiveness. As observed in Taiwan where they co-exist, for example, while $M$. micrantha run rampant and becomes a major pest of crops and forests [36, 37], M. cordata grows slowly and exhibits no harm to other native species and the local ecosystems [38].

Previous studies on the invasion of $M$. micrantha were mainly performed on the species alone and/or focused on its ecological impacts and physiological traits [9, 35, 39-49]. Comparisons between $M$. micrantha and its non-invasive congeners that share morphological and life-history traits is lacking [9, 38, 46, 47]. Among the few comparative studies, one of the most compelling observations is the higher photosynthetic efficiency and capability of acclimation to light observed in M. micrantha compared to $M$. cordata [9, 24, 28, 47], which is considered to be at least partly associated with the invasiveness of $M$. micrantha. Studies on habitat preferences have revealed that $M$. micrantha can invade a relatively wider light niche, while $M$. cordata can only tolerate shady environments in tropical and subtropical China [9, 38, 47, 50, 51]. $M$. micrantha has also been found to be able to achieve extremely fast growth and reproduction in new environments [52], hinting that efficient response to new abiotic and biotic stresses, such as climate, soils, and pathogens $[53,54]$ followed by successful adaptation and range expansion, could be another remedy for its invasiveness. Yang et al. (2017) has also preliminarily associated the ecological adaptation of $M$. micrantha to different habitats with differential expression of genes involved in high light intensity stress response, protein folding, and oxidative processes by comparing native and introduced $M$. micrantha populations [49]. While Huang et al. (2012) also provided a preliminary insight of the $M$. micrantha transcriptome, constrained by the sequencing technology and bioinformatics tools developed then, the size and quality of data obtained at that time was relatively limited for a thorough study [55]. Although these studies have undoubtedly extended our understanding on the invasiveness of $M$. micrantha from the physiological and ecological perspectives (i.e., the physiological plasticity and rapid adaptive regulation), the underlying molecular mechanisms remains barely explored.

Different from intraspecific analysis on gene expression or other physiological characteristics, which has been a 
common method to investigate the adaptive strategies of invasive species $[9,24,28,47,49,56]$, genomic-level interspecific comparisons of closely related invasive and non-invasive congeners would offer further insights into the molecular mechanisms underlying those traits or the genetic basis that confer greater invasive potential to a species. The species pair of $M$. micrantha and $M$. cordata thus offers an ideal system for comparative analysis. To further exclude possible biases due to stochastic factors or phylogenetic effects from comparing only two species, the inclusion of a third, closely related, non-invasive congener in such a study would aid in the reduction of these stochastic effects to more accurately identify the genomic/ transcriptomic features that is unique to the invasive species. In this study, we performed RNA-sequencing (RNA-seq) and assembled the transcriptomes of the invasive plant $M$. micrantha and its coexisting non-invasive congener $M$. cordata from China, and another allopatric non-invasive congener $M$. cordifolia $[57,58]$. In order to construct a phylogenetic framework for downstream comparisons, the relationship among the three species has to be first established. For that, we conducted a phylogenetic analysis and estimated the time and level of divergence among the species. We then performed a series of detailed comparative analyses including on the differences in genomic contents and changes in gene sequences, and assessed the role of evolutionary factors (e.g., natural selection) on the adaptation and invasion potential of $M$. micrantha. The objective of this study was to use large-scale datasets to identify the genetic basis of invasiveness observed in $M$. micrantha, which would be valuable for further unraveling the molecular mechanisms of invasion success and contribute to the control efforts of the species. In particular, we explored: (1) the degree of sequence differentiation among $M$. micrantha, $M$. cordata, and $M$. cordifolia, and the divergence times of these three species; (2) the differences in gene components and expression patterns between the transcriptomes of $M$. micrantha and M. cordata/M. cordifolia and their functional roles; and (3) the evolutionary signatures of $M$. micrantha genes, i.e., the types of genes with putatively accelerated nonsynonymous divergence and genes that show signals of positive selection, and their potential correlations with the adaptability and invasiveness of M. micrantha.

\section{Results}

\section{Transcriptome sequencing and de novo assembly}

Using RNA-seq, a total of 41.26, 48.76, and 46.76 million paired-end reads were generated from the $M$. micrantha, $M$. cordata, and $M$. cordifolia leaf transcriptomes, respectively (Table 1). After trimming and removing low-quality bases and adapter-containing reads, 41.04, 48.76, and 45.53 million high-quality reads data remained for $M$. micrantha, M. cordata, and M. cordifolia, with Q20 percentages (sequencing error rate $<1 \%$ ) of 97.51, 92.34 and $97.37 \%$, respectively. Based on these clean reads, $75,179,76,344$, and 93,872 contigs were de novo assembled for M. micrantha, M. cordata, and M. cordifolia, respectively, which further resulted in 62,145, 56,409, and 53,330 non-redundant sequences with N50 values of 975,1399 , and $1561 \mathrm{bp}$, respectively, suggesting good integrity of the three assemblies. All sequencing reads generated in this study have been deposited in NCBI Sequence Read Archive (SRA) under the accession numbers SRX3520663- SRX3520665.

To ensure the reliability of our data and results, we first identified the putative origin (i.e., plant, animal, fungus,

Table 1 Sequencing, assembly, and annotation statistics for the transcriptomes of M. micrantha, M. cordata, and M. cordifolia

\begin{tabular}{|c|c|c|c|}
\hline & M. micrantha & M. cordata & M. cordifolia \\
\hline Total raw reads (million) & 41.26 & 48.76 & 46.76 \\
\hline Total filtered reads (million) & 41.04 & 48.76 & 45.53 \\
\hline$\% \mathrm{G} / \mathrm{C}$ & 43.98 & 45.32 & 48.50 \\
\hline Number of contigs & 75,179 & 76,344 & 93,872 \\
\hline Number of non-redundant sequences & 62,145 & 56,409 & 53,330 \\
\hline Number of unigenes & 52,179 & 55,835 & 52,983 \\
\hline Maximum length of unigenes (bp) & 6763 & 14,332 & 10,914 \\
\hline Average length of unigenes (bp) & 643 & 843 & 1016 \\
\hline N50 of unigenes (bp) & 1047 & 1406 & 1563 \\
\hline Number of total annotated unigenes & $32,418(62.13 \%)$ & $31,944(57.21 \%)$ & $40,991(77.37 \%)$ \\
\hline Number of unigenes with NR annotations & $29,934(57.37 \%)$ & $29,829(53.42 \%)$ & $39,576(75.00 \%)$ \\
\hline Number of unigenes assigned with GO terms & $19,945(38.22 \%)$ & $27,561(49.36 \%)$ & $31,178(58.85 \%)$ \\
\hline Number of unigenes assigned to KEGG pathways & 10,787 (20.67\%) & $9164(16.41 \%)$ & $23,381(44.13 \%)$ \\
\hline Number of unigenes with KOG annotations & $11,127(21.32 \%)$ & $11,497(20.59 \%)$ & $29,854(56.35 \%)$ \\
\hline
\end{tabular}


bacteria, archaea, virus and viroids, or other) of each non-redundant sequence based on its top-hit BLAST result against the NCBI non-redundant protein (NR) database. The BLAST results showed that for $M$. micrantha, M. cordata, and M. cordifolia, 39,511, 30,380, and 39,893, respectively, of the non-redundant sequences had hits in NR databases. As expected, most sequences (75.76, 98.19, and $99.21 \%$ of all matched sequences) of the three assemblies were of plant origins. A considerable amount of fungus-origin sequences was identified from the $M$. micrantha assembly $(8917,22.57 \%)$ while only some were found in the $M$. cordata $(23,0.076 \%)$ and M. cordifolia $(24,0.060 \%)$ assemblies (Additional file 1). To maximize the accuracy of our data analyses, we then removed the sequences with non-plant-origin. The filtered sequences were considered as non-redundant sequences derived from the three plant species (hereafter 'unigenes') and used in the downstream comparative analyses. As a result, the final unigene sets of $M$. micrantha, M. cordata, and M. cordifolia consisted of 52,179, 55,835, and 52,983 sequences, with similar length and GC distribution patterns (Additional file 2), and N50 values of 1047, 1406, and $1563 \mathrm{bp}$, respectively (Table 1).

To assess the per-base sequence accuracy of the three unigene sets, firstly, all usable reads were mapped to the unigenes and the coverage depth was counted for each site of each sequence. The results showed that, for $M$. micrantha, M. cordata, and M. cordifolia, 99.94, 99.24, and $98.03 \%$ sites in total were covered by at least one high-quality base (Phred quality score $\geq 30$ ), equivalent to an accuracy of $\geq 99.9 \%$ at these sites; and $77.56,61.03$, and $76.04 \%$ sites were covered at least ten times by high-quality bases, equivalent to an accuracy of $\geq 99.99 \%$ (Additional file 3). Additionally, all usable nucleotide sequences available in the NCBI databases so far for the three species $(61,5$, and 29 sequences from 20,4 , and 4 different genes, respectively) were obtained and compared with their corresponding unigenes assembled above. As a result, $M$. micrantha, $M$. cordata, and $M$. cordifolia unigenes showed $98.23-100 \%, 99.91-100 \%$, and $98.34-100 \%$ identity with those from public databases, respectively (Additional files 3 and 4). Finally, for all three species, DNA fragments of 9 randomly chosen unigenes were amplified and sequenced by Sanger sequencing. As a result, all unigene sequences of the three species showed $100 \%$ identity with their respective Sangersequencing-derived sequences, and all interspecific single nucleotide polymorphisms identified from unigene sequences were also verified (Additional file 5). These results indicated high accuracy of most assembled unigenes at the per-base level and minor nucleotide discordance in a few sequences, which should have little effect on the following analyses and results given its small proportion and low degree of variation.

\section{Phylogenetic analysis and divergence time estimation} To investigate the phylogenetic relationships and divergence times for $M$. micrantha, $M$. cordata, and M. cordifolia, a total of 456 1:1 orthologous genes were identified, based on which, a phylogenetic tree was reconstructed for the three Mikania species (Eupatorieae, Heliantheae alliance) and six other species from the Heliantheae alliance, including two species from Eupatorieae (Chromolaena odorata and Stevia rebaudiana), two species from the sister tribe Heliantheae (Ambrosia artemisiifolia and Helianthus annuus) and one species for each of the sister tribe Madieae (Arnica montana) and Helenieae (Helenium autumnale), using Tragopogon dubius (Cichorioideae) as an outgroup. As observed from the phylogenetic tree (Fig. 1a), M. micrantha and M. cordata showed a closer relationship with each other than with $M$. cordifolia. Bayesian estimation of divergence time with confident constraints further suggested that $M$. cordifolia diverged from the Mikania common ancestor approximately 8.70 MYA (95\% credibility interval, CI $=7.5-10.0$ MYA), and that $M$. micrantha and $M$. cordata split approximately 4.81 MYA (95\% CI = 4.0-5.7 MYA).

For further assessment of the genetic divergence among the three Mikania species, their differences in sequences were also measured. Direct comparison on protein sequences of orthologous gene pairs showed an overall similarity of approximately $94.44 \%$ for $M$. micrantha- $M$. cordata, slightly higher than that for $M$. micrantha-M. cordifolia (93.67\%) and M. cordata-M. cordifolia (93.65\%) (Additional file 6). Further estimation under the nucleotide substitution model revealed that the median nonsynonymous substitution rate (Ka) was 0.0125 (Fig. 1b), indicating that about $1 \%$ of each protein sequence differs, between $M$. micrantha and $M$. cordata, which was lower than that between $M$. micrantha and M. cordifolia $(\mathrm{Ka}=0.0183)$ or between $M$. cordata and M. cordifolia $(\mathrm{Ka}=0.0195)$. As for the silent site divergence, the median synonymous substitution rate (Ks) was 0.0560 between $M$. micrantha and $M$. cordata, 0.0976 between $M$. micrantha and M. cordifolia, and 0.0980 between M. cordata and $M$. cordifolia (Fig. 1c). These results collectively suggested a closer relationship, i.e., smaller divergence, between $M$. micrantha and $M$. cordata than any of them with $M$. cordifolia.

\section{Functional annotation and $\mathrm{GO}$ classification}

To understand the functions of the unigenes derived from the three Mikania species in this study, we performed similarity search on these sequences with those in public databases. In total, 32,418 (62.13\%), 31,944 (57.21\%), and 40,991 (77.37\%) of M. micrantha, M. cordata, and M. cordifolia unigenes had matches in at least one database (Table 1; Additional file 7), indicating that our assemblies covered a substantial number of genes of 


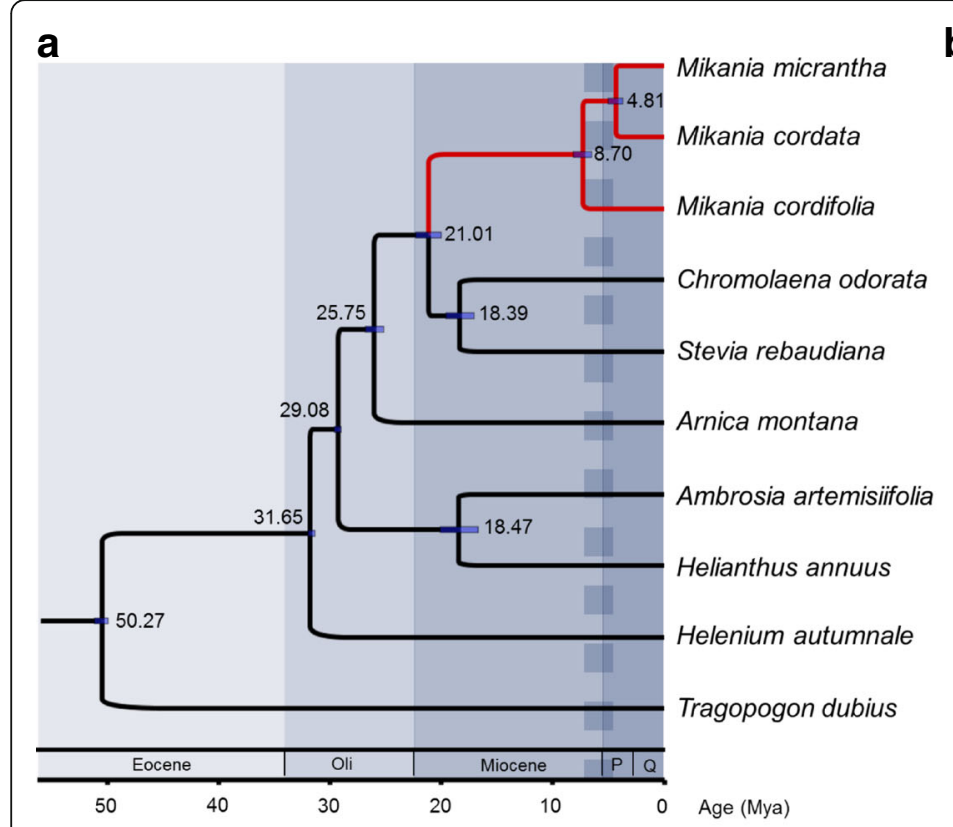

$$
\text { b }
$$

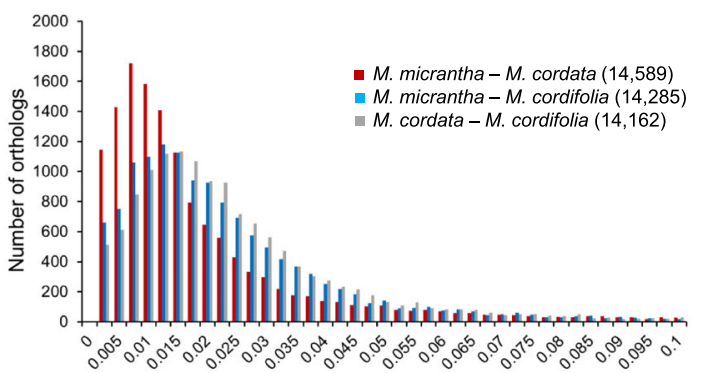

$\mathrm{Ka}$

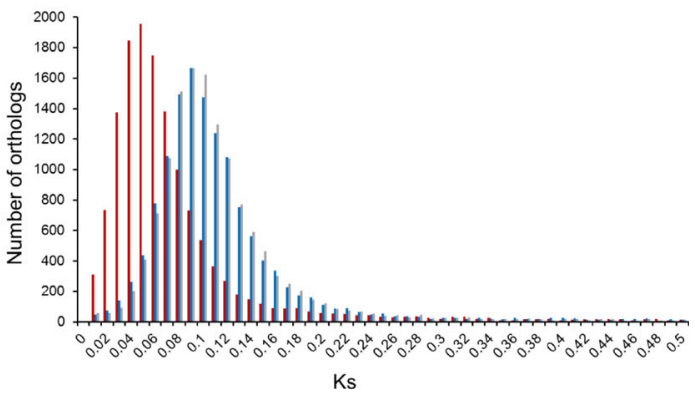

Fig. 1 Phylogeny and divergence times of M. micrantha, M. cordata, and M. cordifolia. a Phylogeny and divergence times for the three Mikania species and seven other species in Asteraceae. The value and purple bar at each node indicate the estimated divergence time with a 95\% credibility interval. b Distribution of nonsynonymous (Ka) and synonymous (Ks) substitution rates of ortholog pairs between the three Mikania species. The numbers in parentheses after the species name indicate the number of ortholog pairs used for plotting

the two species. For M. micrantha, M. cordata, and $M$. cordifolia, among the 29,934 (57.37\%), 29,829 (53.42\%), and $39,576(75.00 \%)$ unigenes with matches in the NR database, 15,377 (51.37\%), 24,624 (82.55\%), and 33,820 (85.46\%) unigenes matched sequences from their respective top ten species, respectively (Additional file 7). Besides, while half of these top species for $M$. micrantha were unsurprisingly of Asterids, most of those for $M$. cordata and $M$. cordifolia belonged to Rosids, indicating potential differences in their genetic components. Besides, the three species showed similar patterns of E-value and sequence similarity in the BLAST hit results (Additional file 7).

Based on the above BLAST search results, GO annotations were then retrieved. For $M$. micrantha, M. cordata, and $M$. cordifolia, 19,945 (38.22\%), 27,561 (49.36\%), and 31,178 (58.85\%) unigenes had GO terms assigned in the three main categories, including 14,388, 22,144, and 24,909 unigenes with terms from "Biological Process", 9226, 20,092, and 26,490 from "Cellular Component", and 17,045, 23,334, and 23,811 from "Molecular Function", respectively. While the gene distribution patterns (at level two) were generally similar among the three transcriptomes (Fig. 2a), detailed comparisons for each functional class (at all GO levels) identified significant differences of gene components among the three Mikania transcriptomes (Fig. 2b; Additional file 8). In total, the enrichment analysis showed 248 and $879 \mathrm{M}$. micrantha GO terms significantly differing from that of $M$. cordata and M. cordifolia, respectively. Among which, 235 and 868 terms, respectively, were overrepresented in $M$. micrantha (Fisher's exact test and false discovery rate (FDR), $P<$ 0.05 ), with most of them (213 out of 235) being shared (Additional file 8). It is worth noting that many of these GO classes enriched in $M$. micrantha are functionally related to photosynthesis, gene transcription/translation, cell cycle, protein modification, and damage repair, such as those involved in "photosystem I reaction center" (GO:0009538, 27 vs. 21 and 12), "photosystem II oxygen evolving complex" (GO:0009654, 44 vs. 34 and 29), "transcription factor activity, protein binding" (GO:0000988, 192 vs. 182 and 139), "protein binding involved in protein folding" (GO:0044183, 23 vs. 17 and 7), wound healing (GO:0042060, 76 vs. 72 and 1), and "metaphase/anaphase transition of cell cycle" (GO:0044784, 21 vs. 20 and 20).

\section{KEGG analysis and KOG classification}

To investigate the active biological pathways of the three Mikania species, KEGG pathway assignments and detailed statistical analysis were performed. For M. micrantha, M. cordata, and M. cordifolia, 10,787 (20.67\%), 9164 (16.41\%), and 23,381 (44.13\%) unigenes were assigned 43 KEGG pathway classes comprising 349, 339, and 350 subclass pathways, respectively (Table 1 ). Although covering similar ranges of pathway classes, the involved genes of the three species also showed differential distributions 


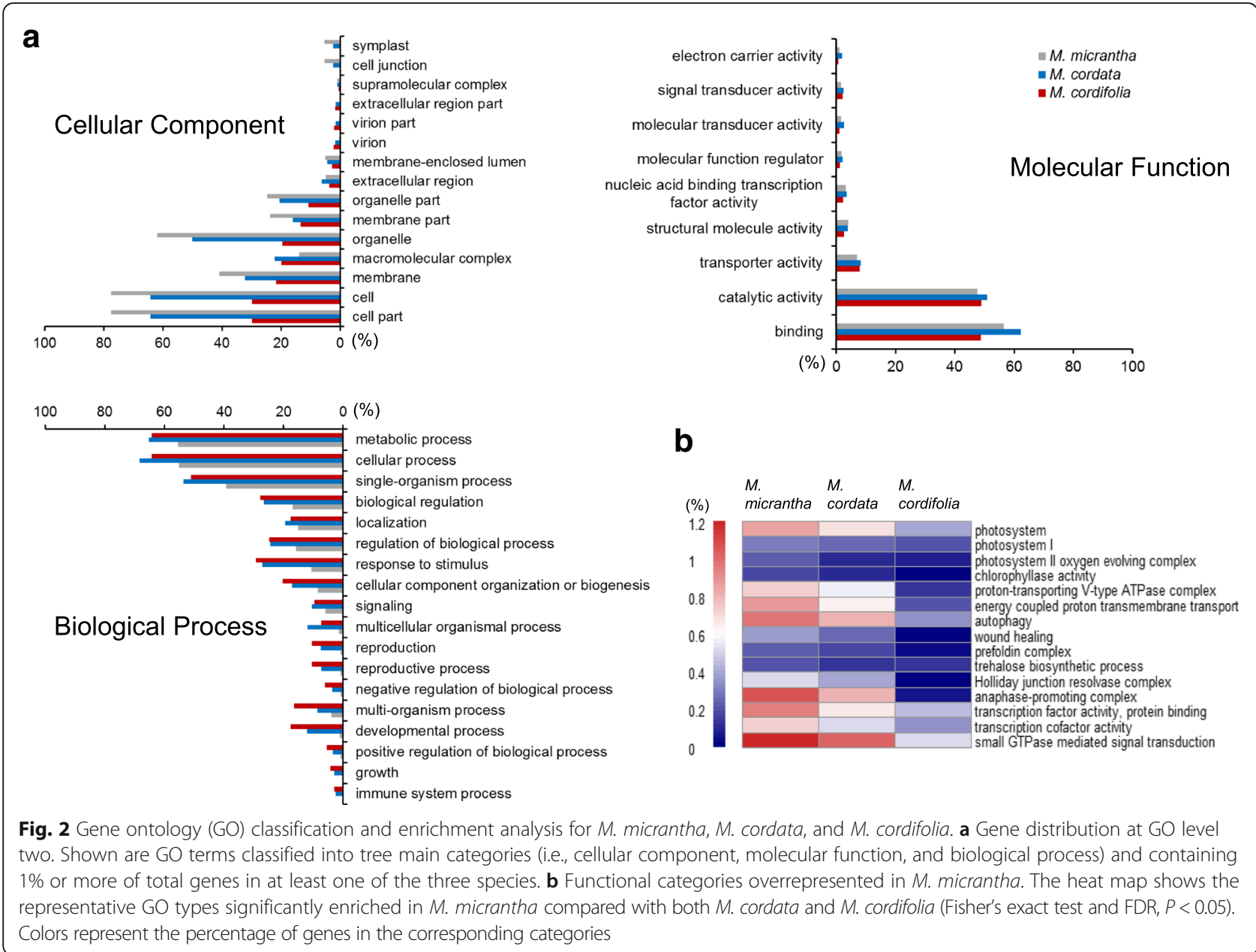

in several pathways, especially between $M$. micrantha/M. cordata and M. cordifolia (Additional file 9). As revealed by statistical analysis for each subclass pathway, $M$. micrantha genes only differed in two subclass pathways compared with $M$. cordata, while a total of $119 / 110$ pathways were significantly different between $M$. micranthal $M$. cordata and M. cordifolia (Fisher's exact test and FDR, $P<0.05)$. Despite the more similar gene distribution patterns between $M$. micrantha and $M$. cordata than between these two species with $M$. cordifolia, which was in accordance to their phylogenetic relationships as mentioned above, it was worth noting that M. micrantha pathway-involving genes showed significantly higher representation than $M$. cordata and M. cordifolia genes in photosynthesis (ko00195; 18.26\% vs. 10.27\%; Fisher's exact test and FDR, $\mathrm{P}<0.05)$, a subclass pathway involved in the energy metabolic pathway.

For more comprehensive annotation, all unigenes of the three Mikania species were subjected to a search against the KOG database. For M. micrantha, M. cordata, and M. cordifolia, 11,127 (21.32\%), 11,497 (20.59\%) and 29,854 (56.35\%) unigenes were classified into 26 KOG categories, respectively (Table 1; Additional file 10). Similar to that in GO terms and KEGG pathways, differences of gene distributions in some KOG categories were also observed among the three species, especially between $M$. micrantha/M. cordata and M. cordifolia. For example, for both $M$. micrantha and $M$. cordata, the most represented functional category was "Posttranslational modification, protein turnover, chaperones" (2161 genes, $19.42 \%$ and 1590 genes, $13.83 \%$ ), followed by "Translation, ribosomal structure and biogenesis" (1487 genes, 13.36\% and 786 genes, 6.84\%) and "Signal transduction mechanisms" (1336 genes, $12.01 \%$ and 1114 genes, 9.69\%), while that for M. cordifolia was "Signal transduction mechanisms" (3958 genes, 13.26\%), followed by "Posttranslational modification, protein turnover, chaperones" (3126 genes, 10.47\%) and "Transcription" (2179 genes, $7.30 \%$ ).

\section{Detection of differentially expressed genes}

To investigate the patterns of gene expression in the invasive and non-invasive Mikania species, the RNA-seq data of $M$. micrantha, $M$. cordata, and $M$. cordifolia were separately mapped to their reference transcriptomes 
(i.e., unigene sets), and genes differentially expressed between $M$. micrantha and $M$. cordata/M. cordifolia were identified. Under a priori replicate variance value of 0.2 and an FDR cut off of 0.01 (Additional file 11), 2088 and 2344 genes exhibited differential expression in M. micrantha-M. cordata and M. micrantha-M. cordifolia, with 1337 and 1724 genes up-regulated and 751 and 620 genes down-regulated in M. micrantha compared with M. cordata and M. cordifolia, respectively. Among them, 650 up-regulated and 241 down-regulated genes were shared between the two comparisons (Additional file 12). After GO term assignment, these shared up-regulated genes were found to be involved in $1747 \mathrm{GO}$ categories (at all levels), including "response to stress", "response to starvation", "defense response", and "response to DNA damage stimulus" (Additional file 13).

\section{Accelerated evolution analysis and identification of positively selected genes}

To examine the type of genes that showed accelerated evolution and also identify genes under positive selection pressure for the three Mikania species, a total of 4513 orthologs within a group of five Eupatorieae (i.e., $M$. micrantha, M. cordata, M. cordifolia, $C$. odorata, and $S$. rebaudiana) and one Madieae (i.e., A. montana, as an outgroup) species was identified. These genes were functionally grouped into 642 different categories according to their GO annotations and used to detect the types of genes showed accelerated evolution. To infer average rates of protein evolution for different GO categories between invasive and non-invasive Mikania species, both $M$. micrantha-M. cordata and M. micrantha-M. cordifolia ortholog pairs were compared. For those between non-invasive Mikania species, M. cordata-M. cordifolia ortholog pairs were compared. Preliminary analysis on $\mathrm{Ka} / \mathrm{Ks}$ ratios of nonsynonymous-to-synonymous substitutions for each group of genes revealed elevated Mikania pairwise $\mathrm{Ka} / \mathrm{Ks}$ values in diverse functional categories (top $10 \%$ fastest evolving categories; Additional file 14), among which, genes related to carbon fixation and chlorophyll biosynthetic were notably present in the fastest evolution categories between invasive and non-invasive Mikania (i.e., both M. micrantha-M. cordifolia and M. micrantha- $M$. cordata) while being absent in those between non-invasive Mikania (i.e., M. cordata-M. cordifolia).

Further statistical comparisons showed that the average $\mathrm{Ka} / \mathrm{Ks}$ in several categories, e.g., carbon fixation (0.61 vs. 0.37$)$, chlorophyll biosynthetic process (0.49 vs. $0.26)$, cellular response to stress (2.77 vs. 1.66$)$, DNA repair (11.38 vs. 5.55$)$, chromosome organization ( 0.23 vs. $0.19)$, and transcription cofactor activity ( 0.52 vs. 0.43$)$, was significantly higher in $M$. micrantha-M. cordata than in $M$. cordata-M. cordifolia $(P<0.05$ by Fisher's exact test; Fig. 3a; Additional file 15). Categories with similar functions (e.g., chlorophyll biosynthetic process, 0.37 vs. 0.26 ) were also observed when comparing $M$. micrantha-M. cordifolia with $M$. cordata-M. cordifolia, indicating that the average rate of protein evolution for these genes is faster between invasive and non-invasive than in between non-invasive Mikania by a significant margin. When estimating the number of genes that showed higher $\mathrm{Ka} / \mathrm{Ks}$ in $M$. micrantha-M. cordata/M. cordifolia than in M. cordata-M. cordifolia or vice versa, however, it was found that in most of these categories the number of genes with higher $\mathrm{Ka} / \mathrm{Ks}$ in $M$. micrantha-M. cordata/M. cordifolia were not significantly higher than the other way around $(P>0.05$ by the binomial test), arguing that for these categories the higher average $\mathrm{Ka} / \mathrm{Ks}$ in between invasive and non-invasive Mikania is mainly contributed by certain genes instead of the combined effects of a large fraction of all genes involved. This implication was further supported by the statistical tests on $\mathrm{Ka} / \mathrm{Ks}$ distributions, which revealed that the M. micrantha-M. cordata/M. cordifolia distributions were not significantly different from the $M$. cordata- $M$. cordifolia distributions $(P>0.05$ by the Wilcoxon signed-rank test).

Lineage-specific analysis revealed relatively slower evolutionary rates for most $M$. micrantha genes than those of $M$. cordata and M. cordifolia, as revealed by their median $\mathrm{Ka} / \mathrm{Ks}$ values of all orthologous genes calculated using the free-ratio model (i.e., $\mathrm{Ka} / \mathrm{Ks}$ of 0.0981, 0.1382, and 0.1275 for M. micrantha, M. cordata, and M. cordifolia, respectively), which can also be observed through the distributions of these $\mathrm{Ka} / \mathrm{Ks}$ values that showed relatively more $M$. micrantha genes in the very low $\mathrm{Ka} / \mathrm{Ks}$ range (i.e., $\mathrm{Ka} / \mathrm{Ks} \leq 0.05$; Additional file 16). These results might suggest that compared with $M$. cordata and $M$. cordifolia, the majority of $M$. micrantha genes were less likely to be changed while some genes might be under excess evolutionary pressure (i.e., positive selection) and of special significance for the species. To provide full lists of candidate genes that have been under positive selection in the invasive $M$. micrantha and understand their functional importance, positively selected genes (PSGs) were identified along each Mikania branch using the improved branch-site likelihood ratio test. In total, 213, 225, and 178 PSGs were identified, with 112, 114, and 65 genes left after correcting for multiple tests (FDR, $P<0.05$ ) for $M$. micrantha, M. cordata, and M. cordifolia, respectively (Fig. 3b; Additional file 17). Of the $112 M$. micrantha PSGs, 85 genes were assigned to 857 terms of the three main GO categories, and 43 were assigned to $72 \mathrm{KEGG}$ pathways. Enrichment tests for all GO hierarchies revealed that these PSGs were significantly overrepresented compared to the background level $(P<0.05$, Fisher's exact test and FDR) in categories including chlorophyll biosynthesis, ATPase activity, response 


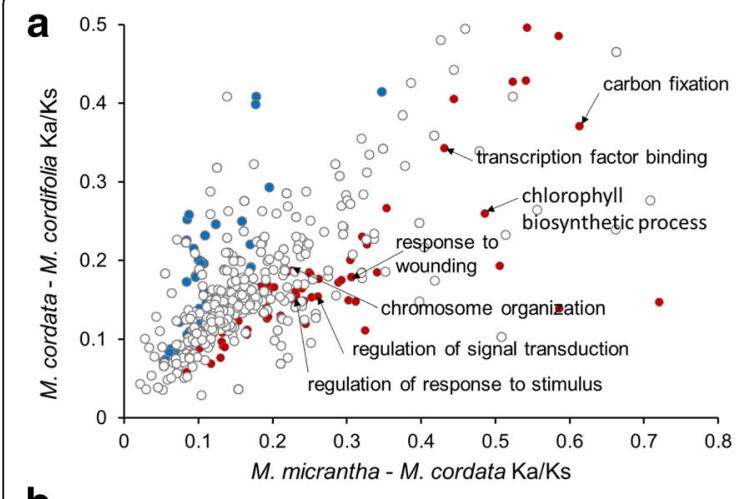

b

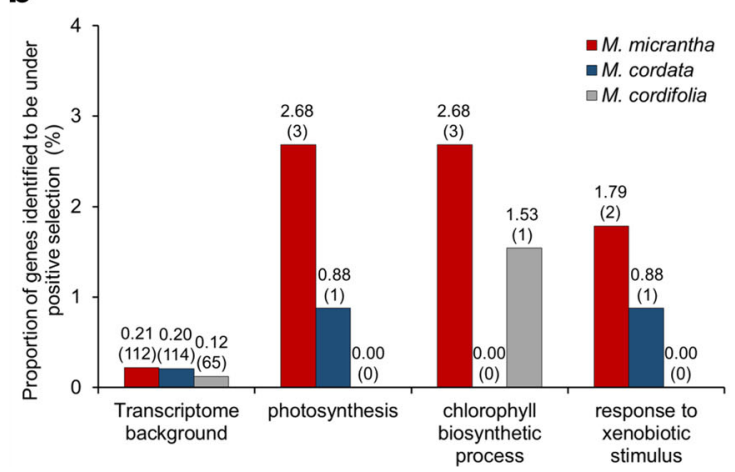

C

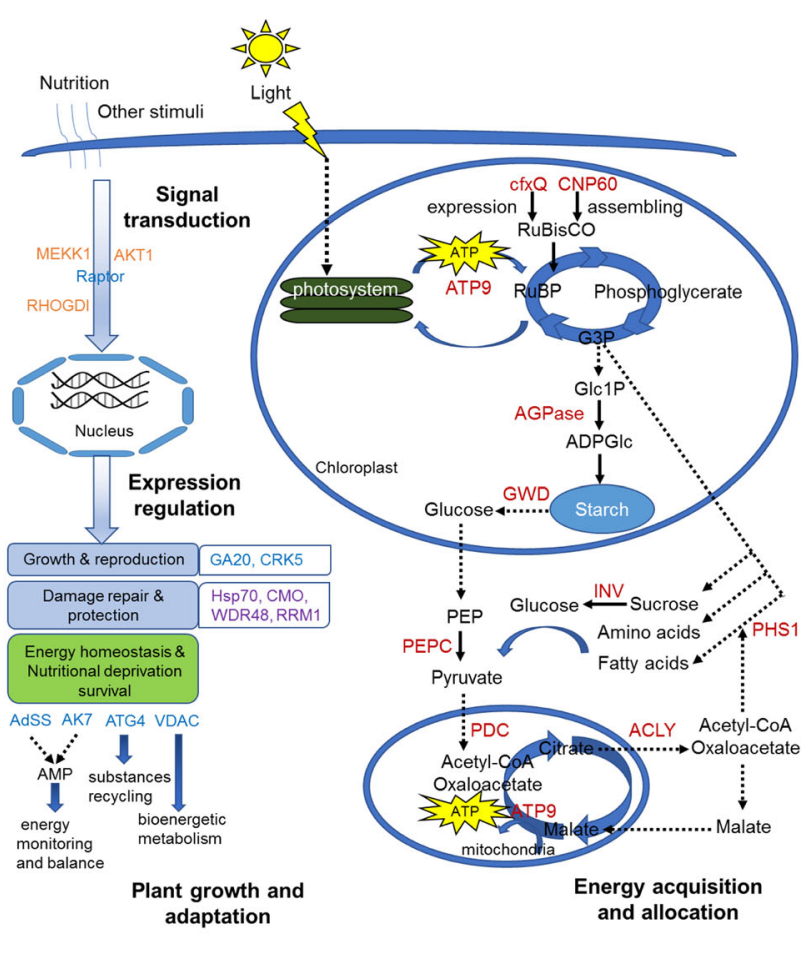

Fig. 3 Evolutionary signals in M. micrantha. a Mikania pairwise Ka/Ks for each GO term. Data points represent average Ka/Ks ratios of M. micrantha-M. cordata and M. cordata-M. cordifolia pairs by GO category. GO categories with putatively accelerated ( $P<0.05$, Fisher's exact test) nonsynonymous divergence in $M$. micrantha-M. cordata are highlighted in red while those in M. cordata-M. cordifolia are in blue. $\mathbf{b}$ Comparison of positively selected genes (PSGs) in M. micrantha, M. cordata, and M. cordifolia. The number of PSGs shown in different categories were obtained based on their GO classification and are given in parentheses. c Positively selected genes involved in energy utilization and stimuli response processes. Genes that showed evidence of positive selection in M. micrantha are in red, blue, purple, and orange for group I, II, III, and IV PSGS, respectively. Solid lines indicate direct relationships between enzymes and metabolites, while dashed lines indicate that more than one step is involved in the process

to stimulus, protein folding, and chromosome segregation (Additional file 18). After thorough exploration on gene functions for each PSG, most $M$. micrantha PSGs (77, 68.75\%) were found to be mainly involved in processes of i) energy acquisition and utilization, ii) growth and reproduction, iii) protection and repair, and iv) signal transduction and biological regulation, which might have contributed to the specific traits, e.g., wide eco-adaptability and intense invasiveness, of M. micrantha (Fig. 3c).

\section{Discussion}

\section{Recent divergence between the invasive $M$. micrantha} and the non-invasive $M$. cordata

Mikania belongs to Eupatorieae under the subfamily Asteroideae and family Asteraceae, one of the largest angiosperm families with over 24,000 species $[59,60]$. Huang et al. (2016) performed an elaborate analysis of the phylogeny, divergence, and polyploidization of 73 Asteraceae species, providing evidences for the correlations among polyploidization, stressful environments, and new open niches after mass extinction, as well as the species radiation of Asteraceae into large subfamilies or tribes [60]. Since their study mainly focused on the large subfamilies or tribes, divergences between small groups (e.g., within genus) were barely mentioned. In this study, further estimation of the divergence times using 456 single copy orthologous genes suggested that the split of the three Mikania species occurred during or soon after the late Miocene (5.3-11.2 MYA), with $M$. cordifolia diverging first (8.70 MYA, 95\% CI $=7.5-$ 10.0 MYA), followed by the split of $M$. micrantha and M. cordata (4.81 MYA, 95\% CI = 4.0-5.7 MYA) (Fig. 1). The late Miocene is an important geological epoch for the evolution of global climate [61-63]. Severe environmental changes during the late Miocene generated a greater diversity of habitats and led to a rediversification of temperate and tropical ecosystems [64], which could be responsible for the diversification of Mikania through adaptive speciation.

For M. micrantha and M. cordata, particularly, the differing habitat conditions (i.e., sunny vs. semi-shaded 
areas) derived from the late Miocene environmental changes might have driven the subsequent divergence of their ancestral populations and promoted the accumulation of genetic differences that are of benefit for adaptation to their respective habitats. Although the present-day morphological features of $M$. micrantha and M. cordata are still so similar that it is difficult to distinguish them with the naked eye [47], the several million years of evolution still resulted in considerable genetic differences between the two species, as observed in differences in the number of genes $(52,179$ vs. 55,835$)$ and gene sequence $(\mathrm{Ka}=0.0125$ and $\mathrm{Ks}=0.0560)$ obtained in this study. Given the distinct niche requirements and different invasion capabilities between $M$. micrantha and $M$. cordata, the detected genetic divergence could be the underlying cause for the higher eco-adaptability of M. micrantha, giving it the potential to invade various habitats (e.g., wider light niche).

\section{Overrepresented functional categories may represent unique molecular characteristics associated with the invasiveness of $M$. micrantha}

The successful invasion of a plant species comprises firstly the adaptation to and colonization of a new habitat, followed by the rapid range expansion in introduced region. These are greatly correlated with biological processes like acclimation to important environmental factors, response to various environmental stimuli, together with fast growth and reproduction. These complex processes usually involve multiple genes underlying the relevant biological characteristics across the transcriptome, thus a comparison of transcriptomes between the invasive species and its non-invasive congener could unravel specific genetic components that might have contributed to its successful invasion. In this study, detailed comparison of GO classifications between transcriptomes of $M$. micrantha and its indigenous sister species $M$. cordata revealed noteworthy differences between these two species. M. micrantha was found to harbor far more overrepresented GO categories than M. cordata (235 vs. 13). Notably, most of these $M$. micrantha-enriched functional categories (213 out of $235,90.64 \%$ ) also had higher representation in $M$. micrantha when compared to $M$. cordifolia (Fisher's exact test and FDR, $P<0.05$ ), and several of them were found to be involved in photosynthesis, energy metabolism, wound healing, protein modification, asexual reproduction, and biological regulation process (Additional file 8), hinting at the special significance of these functions to the physiology of the invasive $M$. micrantha. Moreover, comparison of genes in each KEGG pathway between $M$. micrantha and $M$. cordata identified an enrichment of $M$. micrantha genes involved in the photosynthesis pathway (ko00195, a subclass of energy metabolism) (Fisher's exact and FDR,
$P<0.05)$, which was, again, identified for $M$. micrantha in its comparison to $M$. cordifolia (Additional file 9). The marked differences in gene contents of these specific functions between $M$. micrantha and both of its non-invasive congers may be at least partly responsible for their differences in eco-adaptability and invasiveness.

Besides gene contents, we also tested if the differential invasiveness between species were reflected in the patterns of their gene expression. As our study primarily emphasized on the comparative transcriptomics and evolutionary analysis, the experimental design was not well suited for rigorous detection of differentially expressed genes. However, procedures implemented in EdgeR [65] allow us to gain some preliminary observations under such situation by setting a priori for the replicate variance. Thus, we used a conservative approach (i.e., assuming a high error variance) to detect genes differentially expressed between the invasive and non-invasive Mikania species. After trying a series of variance values, 0.2 was as the final setting. We found that the number of significantly up-regulated genes (1337 and 1724) was much larger than that of down-regulated (751 and 620) in M. micrantha compared with M. cordata or M. cordifolia (Additional files 11). This trend was still obvious when considering the genes jointly up-regulated (650 genes) or down- regulated (241 genes) in $M$. micrantha compared with both $M$. cordata and $M$. cordifolia, suggesting that these up-regulated genes might have important functions to the invasive characteristics of $M$. micrantha (Additional file 12). Statistical tests $(F D R<0.05)$ indicated that functional categories such as chlorophyllase activity, response to stress, response to nutrient levels, protein processing and DNA repair were significantly overrepresented in this set of genes Additional file 13). Notably, although a conservative method was adopted, the differentially expressed genes detected here should still be treated with caution because of the lack of biological replicates. Combined with the gene contents patterns discussed above, it is reasonable to speculate that the higher representation of these genes might be beneficial for improving the photosynthetic rate, energy and resources supply, damage repair capability, and other cellular regulation efficiency of M. micrantha.

\section{Gene classes showing accelerated evolution between $M$. micrantha and congeners may be important for invasiveness} Besides the differences in genetic components as discussed above, characterization of the patterns of sequence divergence across the genomes could further help to clarify the evolutionary processes that gave rise to the distinct features between species, and even the genetic basis and mechanisms of adaptive evolution and speciation [66-68]. Rapid evolutionary change, i.e., accelerated evolution, has been shown to be a molecular correlate of several biological phenomenon such as phenotypic evolution, 
population divergence, and adaptive evolution [69-72]. In this study, pairwise analysis of nonsynonymous-tosynonymous substitutions for different GO categories revealed that the average evolutionary rates were significantly higher in $M$. micrantha- $M$. cordata than in $M$. cordata-M. cordifolia $(P<0.05$ by Fisher's exact test $)$ for genes in carbon fixation, chlorophyll biosynthesis, cellular response to stress, DNA repair, and transcription regulation (Additional file 15). As several of these similar functional categories were also observed for $M$. micrantha-M. cordifolia in comparison to M. cordata-M. cordifolia, these results jointly indicated that these gene classes generally evolved faster between the invasive and non-invasive, than between the two non-invasive, Mikania species. The corresponding impacts on the related biological processes, especially photosynthesis and stress response, may then have special significance to the invasiveness of $M$. micrantha. This makes sense considering that, in contrast to their indigenous congeners, invasive plants usually face new living conditions very different from their original habitats, and successful establishment there may require efficient response to various accompanying environmental stresses, as well as more efficient energy production for rapid growth and reproduction. Another notable finding was that the higher average evolutionary rate of these functional classes was likely to be contributed by a small fraction of genes involved instead of the majority of these genes, as revealed by statistical tests on the inequality in the number of genes with higher $\mathrm{Ka} / \mathrm{Ks}(P>0.05$, binomial test) and the distinction of $\mathrm{Ka} / \mathrm{Ks}$ distribution between species pairs. This could be plausible considering the relatively recent divergence of these Mikania species, especially between $M$. micrantha and M. cordata.

\section{Positive selection of key genes in $M$. micrantha could have contributed to its invasiveness}

As lineage-specific $\mathrm{Ka} / \mathrm{Ks}$ analysis showed a slower overall rate of protein evolution in $M$. micrantha (median $\mathrm{Ka} / \mathrm{Ks}=0.0981$ ) than those in $M$. cordata and $M$. cordifolia (median $\mathrm{Ka} / \mathrm{Ks}=0.1382$ and 0.1275 , respectively), these results, combined with the pairwise analysis discussed above, suggested that pronounced molecular evolutionary changes may preferentially imprint on certain genes in $M$. micrantha while the majority of genes are less likely to be changed. Since genes performing basic cellular functions conserved across different species should have evolved predominantly under constraint [70], genes under evolutionary pressures (i.e., positive selection) may be important for the specific lifestyle of a species or the adaptive traits crucial for the species' survival and spread in stressful environments [68, 71, 72]. Therefore, having a full picture of the positively selected genes for the invasive $M$. micrantha would be very helpful for the better understanding of the molecular correlates for its strong invasiveness. To this end, signatures of positive selection were tested for all orthologous genes along each Mikania branch using the improved branch-site model [73]. Of the 213 genes that exhibited significant heterogeneity in $\mathrm{Ka} / \mathrm{Ks}$ along the protein sequences with one or more site classes possessing $\mathrm{Ka} / \mathrm{Ks}>1$ (Likelihood ratio test, $P<0.05), 112$ of them showed a significant signature of positive selection after correcting for multiple tests (FDR, $\mathrm{P}<0.05$ ) (Additional file 17). Among which, 77 PSGs were found to be heavily relevant to the wide eco-adaptability and intense invasiveness of $M$. micrantha and could be further classified into four groups, with 10 genes in energy acquisition and utilization (group I), 13 genes in growth and reproduction (group II), 34 genes in protection and repair (group III), and 20 genes in signal transduction and biological regulation (group IV) (Fig. 3; Additional file 17), as discussed in detail below.

As an energy source and regulatory signal throughout the plant life cycle, light is among the most important environmental factors affecting the optimal growth and development of plants, especially vines [74-76]. The capability of light capture and utilization is therefore of particular relevance to the establishment, competition, and expansion of invasive plants [77]. For the invasive vine $M$. micrantha, physiological and biochemical studies have demonstrated its greater photosynthesis capability than $M$. cordata as well as several other associated species $[9,47,78]$. The underlying genetic basis, however, has never been investigated at the molecular level, until now. In this study, 10 genes under positive selection in $M$. micrantha were found to be associated with energy acquisition and utilization (i.e., photosynthesis and photorespiration) (Fig. 3; Additional file 17). Particularly, GF_1026 encodes the cfxQ (carbon fixation Q) protein homolog, known to be essential for the expression of RuBisCO (ribulose 1,5-bisphosphate carboxylase) [79]; and GF_2511 encodes the RuBisCO large subunit-binding protein subunit alpha (CNP60), which is necessary for the assembly of the RuBisCO subunits into an integrated enzyme and also functions in the folding and protection of proteins as a chloroplast chaperone protein [80, 81]. Since $\mathrm{RuBisCO}$ is well known as a key enzyme for carbon fixation during photosynthesis while also participating in photorespiration, these genes could be vital for the photosynthetic efficiency of plants. Besides, while GF_1627 encodes a rate-limiting enzyme of starch synthesis (glucose-1-phosphate adenylyltransferase, AGPase) [82], GF_2051 encodes an enzyme (glucan water dikinase, GWD) acting on the initial event of starch degradation [83]. Since starch is the primary energy reserve in higher plants, these genes are vital for the metabolism and growth of plants. Collectively, the positively selected group I genes may improve the net photosynthetic rate of $M$. micrantha, allowing it to acclimatize to high light 
environments (and thus wider light niche), which in turn provides ample carbon for growth and reproduction [9].

Another most representative characteristic of $M$. micrantha is its extremely fast growth and strong reproduction [84]. Unlike its indigenous sister species $M$. cordata, M. micrantha grows very fast, e.g., the stem tip can elongate up to $20 \mathrm{~cm}$ a day under suitable conditions in summer [37], and has strong capability of asexual (e.g., can take root anywhere in the stem node) $[5,22]$ and sexual reproduction (e.g., large amount of seeds that spread and germinate easily) [28]. Group II PSGs in M. micrantha is comprised of genes involved mainly in cell growth, shoot/root development, seed germination, energy homeostasis (e.g., during nutrient deprivation), and other hormone-related processes that regulate plant growth and development (Fig. 3; Additional file 17). For example, GF_982 encodes cysteine protease ATG4 that is required for autophagy, a strategy that eukaryotic cells use to survive nutritional deprivation through degradation and digestion of non-essential cytoplasmic materials for reuse in essential biosynthetic processes [85]. The product of another gene GF_2509 (regulatory associated protein of mTOR, raptor) is also involved in the signaling pathway that regulates cell growth in response to nutrients and growth factors; this gene has been further found to function in the controls of seed morphology, viability, and germination potential [86, 87]. Besides, GF_4172 encodes a phosphotransferase enzyme (adenylate kinase 7, AK7) that plays an important role in cellular energy homeostasis [88] and GF_3237 encodes the voltage-dependent anion channel (VDAC) protein which plays a role in mitochondrial physiology and bioenergetics metabolism [89]. Positive selection of these genes could be beneficial for improving the sensitivity and response of $M$. micrantha to nutrient levels and energy sufficiency, and contribute to its survival even in poor environments. In addition, GF_1791 encodes the D14 homolog that participates in inhibition of shoot branching, which is one of the critical determinates of aerial plant architecture [90], and GF_1505 (CDPK-related kinase 5, CRK5) is required for primary root elongation and root gravitropic response, the inactivation of which causes a root gravitropic defect and stimulates lateral root formation [91]. Positively selection of these genes might be at least partly responsible for the high reproductive allocation and phonotypic plasticity (e.g., sufficient regulation of different reproductive strategies in different living conditions) of $M$. micrantha that confers it the ability to rapidly expand in its range.

Undeniably, the capability of efficient response by an invading species when faced with new environmental stresses determines its survival in new habitats. For $M$. micrantha, successful invasion worldwide would hardly have realized without sufficient cellular protection strategies in response to various biotic and abiotic stresses. Most of the group III PSGs identified in M. micrantha were found to be associated with the protection and damage repair in cell, including genes involved in cell cycle control, DNA replication and repair, and the proper translation, folding, and degradation of proteins (Fig. 3; Additional file 17). GF_2718, especially, encodes the heat shock $70 \mathrm{kDa}$ protein (Hsp70), which functions in facilitating the folding of nascent and denatured proteins and has been widely known to be essential for the cell to survive environmental stresses [92]. Positive selection of these genes may be essential for the accurate maintenance of genomic materials in cell division during the plant's rapid growth, as well as the protection of cellular macromolecules to ensure normal functionality even in stressful conditions. M. micrantha has demonstrated the capability of dispersing in saline soils by seed and vegetative propagation and has invaded the coastal saline habitat of Guangdong and Hong Kong areas in China [5]. The two PSGs, GF_896 (stress response protein NST1-like) and GF_1847 (choline monooxygenase, CMO), might have at least partly contributed to the salt tolerance of M. micrantha, for NST1 may act as a negative regulator of salt tolerance, while $\mathrm{CMO}$ catalyzes the committing step in the synthesis of glycine betaine, a well-known osmoprotectant accumulated by many plants in response to salinity and drought [93]. Besides the functional genes discussed above, group IV PSGs mainly functions upstream of biological processes and pathways, e.g., transcription regulation and signal transduction, which may be important for the sensitivity to environmental stimuli and promote efficient downstream processes in response to these stimuli.

\section{Conclusion}

Large-scale molecular-level comparison between the invasive $M$. micrantha and its non-invasive congeners $M$. cordata and M. cordifolia is informative in understanding the molecular basis of plant invasion. In this study, we generated transcriptome data for the three Mikania species and examined the genetic basis underlying the invasiveness of $M$. micrantha. Divergence time analysis suggested that the drastic environmental changes and the accompanied habitat diversification during the late Miocene epoch may be responsible for the diversification of Mikania. As revealed in this study, despite the broad similarities between $M$. micrantha and M. cordata/M. cordifolia in general patterns of gene distribution and sequence divergence, the several million years of evolution did result in remarkable differences between the invasive and non-invasive species in gene content, gene expression pattern, and gene evolutionary rate of some specific functional categories, which may have resulted in the higher eco-adaptability and invasiveness of $M$. micrantha. 
Moreover, evolutionary analysis suggested that positive selection has also played an important role in the evolution of $M$. micrantha's capability of adaptation to various habitats and thus promote its invasion. This study primarily emphasized on comparative transcriptomics and evolutionary analysis, and since only one individual was selected to represent each species, inclusion of more biological replicates and more rigorous studies on differential gene expression will provide extra insight into the molecular characteristics of plant invasion. Besides, although the maturing next-generation sequencing technologies and data processing procedures provide guarantee for the quality of derived sequences, a degree of base uncertainty may still occur in some sequences. We therefore recommend examination of per-base accuracy to be performed when necessary, and their potential effects on downstream analysis, even if minimal, should be noted for better guidance of future studies. Nevertheless, findings through this study advances the current understanding of the divergence of Mikania species and the genetic basis of $M$. micrantha's invasion success, which will contribute to better control and prevention efforts.

\section{Methods}

\section{RNA extraction and transcriptome sequencing}

Two seedlings, each representing $M$. micrantha and M. cordata, were collected from Taipei, Taiwan, China $\left(24^{\circ} 50^{\prime}, 121^{\circ} 32^{\prime}\right)$. M. cordifolia seeds from Hillsborough Co. Florida, USA, were sown in a greenhouse, and one resulting seedling was used for RNA extraction experiments. The taxonomic identification of the plant material was undertaken by Dr. Ying Liu in Sun Yat-sen University. Voucher specimens ( $Y$. liu 16,283, Y. Liu 16,252, and Y. Liu 17,384 for the M. micrantha, $M$. cordata and $M$. cordifolia samples, respectively) were deposited at the herbarium of Sun Yat-sen University (SYS). The seedlings were grown under the same condition for two months before their leaves were used for RNA extraction. One individual was sampled for each species, and total RNA was extracted separately from each individual using an improved CTAB method [94] immediately after harvesting. RNA integrity was then checked through 1.0\% agarose gel electrophoresis and on an Agilent 2100 Bioanalyzer (Agilent Technologies, CA, USA). The qualified RNA samples were then subjected to library construction following manufacturer's protocol (Illumina Inc. San Diego, CA, USA). A cDNA library was constructed for each sample and paired-end sequencing was performed on an Illumina HiSeq platform.

\section{Data processing and de novo assembly}

For each library, raw sequencing reads were first examined using FastQC [95] for quality control. To minimize sequencing errors, reads that were contaminated with adapter sequences, contained $\mathrm{N}$ bases accounting for $>10 \%$ of the total read length, or had low-quality (Phred value $\leq 5$ ) bases $>50 \%$ of the total read length, were excluded from further analysis using in-house Perl scripts. Remaining read pairs were regarded as high-quality reads, and were de novo assembled into contigs using Trinity [96] with default parameters. The sequencing reads data has been deposited in the NCBI Sequence Read Archive (SRA) with the accession number SRX3520663- SRX3520665.

After removing contigs with lengths $<200 \mathrm{bp}$, the longest sequence of each locus was selected to represent each gene, and the resulted sequence set was regarded as the non-redundant set of transcripts. To further improve reliability, the putative origin (i.e., plant, animal, fungus, bacteria, archaea, virus and viroids, or other) of each non-redundant sequence was inferred by homology search against the NCBI non-redundant protein (NR) database (BLASTX, $1 \mathrm{e}^{-6}$ ). Those with top-hits against sequences from non-plant organisms were excluded from downstream comparative, phylogenetic, and evolutionary analyses; while the remaining sequences were regarded as unigenes derived from the plant ('unigenes' hereinafter).

For all unigenes, three strategies were adopted to assess their accuracy at the per-base level. Firstly, for each species, all clean reads were mapped to the reference sequences (unigenes) using BWA [97], and the coverage depth of high quality bases (Phred quality score $\geq 30$ ) at each site of each sequence was counted using SAMtools [98] and in-house Perl scripts. Secondly, all available nucleotide sequences of the three species in the NCBI databases were identified by keyword search; after removing chloroplast genome, microsatellite, and other unrelated sequences, the remaining sequences were downloaded and compared with their corresponding assembled unigenes using Blat [99], and their identities were obtained by examining the match or mismatch at each site. Finally, primer pairs were designed from nine randomly chosen unigenes for all three species; after DNA amplification and Sanger sequencing, these sequences were compared with their corresponding assembled unigenes, and the concordance levels were obtained. It should be noted that if a Sanger-sequencing-derived sequence contains intron region, this sequence will not be completely align to its corresponding unigene and thus the "amplified length" and "match length" will be different (Additional file 5).

\section{Functional annotation and enrichment analysis}

To annotate the assembled unigenes, each unigene sequence was first aligned against the NR database using BLASTX with an E-value cutoff of $1 \mathrm{e}^{-6}$. Gene Ontology (GO) terms were then assigned based on the top hits following the BLAST2GO [100] pipeline. Attribution of metabolic pathways and Enzyme Commission (EC) numbers was performed by mapping to the Kyoto Encyclopedia 
of Genes and Genomes (KEGG) database. Clustering of orthologous groups was performed by BLASTP alignments on the Eukaryotic Orthologous Group (KOG) database. Mapping of annotations to the NCBI non-redundant nucleotide (NT) database and the SwissProt database were also performed for more comprehensive annotation of assembled unigenes. To compare the genomic contents between species, GO enrichment analysis was conducted using GOBU [101]. Fisher's exact test was used to test significance of difference between species in each KEGG pathway. Multiple comparisons were corrected using the false discovery rate (FDR) control method.

\section{Differential gene expression analysis}

For M. micrantha, M. cordata, and M. cordifolia, the reads were mapped to their respective unigene sets using BOWTIE2 [102]. Only read pairs that mapped uniquely to a single locus of the reference sequences and had mapping quality larger than 20 were included in further analysis. Based on the mapping results, the number of aligned reads was counted for each sequence using HTSeq [103]. After excluding genes with CPM (count per million) less than 10 in any of the three species, differentially expressed genes were detected for the $M$. micrantha-M. cordata and M. micrantha-M. cordifolia species pairs using the EdgeR package [65], which treat count data with negative binomial models and provide a number of tests to detect differential expression. Since there were no biological replicates in the current data set, we set a priori value for biological replicate dispersion and used the exact test in the "classic" framework, as suggested by the EdgeR developer. After trying a series of different values, the most conservative one (i.e., 0.2) was selected to look for differentially expressed genes in this study. The GO enrichment analysis for differentially expressed genes were performed using the Fisher's exact test in GOBU, and the resulting $P$-values were corrected for multiple testing using the FDR method.

\section{Sequence variation of $M$. micrantha, $M$. cordata, and $M$. cordifolia orthologs}

For each species, the open reading frame and protein sequence of each unigene were obtained based on their BLASTX results against the NR database. To evaluate the sequence divergence among the three Mikania species, putative orthologs of each species pair were first retrieved based on the bidirectional best hits of their proteome sequences using BLASTP. For each ortholog pair, protein sequences were aligned using ClustalW2 [104] with default parameters and then back-translated to alignments of corresponding codon sequences using PAL2NAL [105]. The synonymous (Ks) and nonsynonymous $(\mathrm{Ka})$ substitution rates of the ortholog pairs were estimated with the pairwise likelihood method in PAML [73].

\section{Identification of single-copy ortholog groups and estimation of divergence time}

To reconstruct a phylogeny and estimate the times that the three Mikania have diverged, transcriptome data of six other species from the Heliantheae alliance (i.e., Chromolaena odorata, Stevia rebaudiana, Ambrosia artemisiifolia, Helianthus annuus, Arnica montana, and Helenium autumnale) and one species from Cichorioideae (i.e., Tragopogon dubius, as an outgroup) were downloaded from the NCBI database and used in the phylogeny reconstruction and divergence time estimation, referring to the work by Huang et al. (2016) [60]. Protein sequences of the ten species (i.e., M. micrantha, M. cordata, M. cordifolia, C. odorata, S. rebaudiana, A. artemisiifolia, H. annuus, A. montana, $H$. autumnale, and $T$. dubius) were combined to perform an all-against-all comparison using BLASTP with E-value cutoff of $1 \mathrm{e}^{-10}$. All similar sequences were subsequently processed and clustered into gene families using OrthoMCL [106]. Putative single-copy ortholog groups among the ten species were then retrieved from the clustering results using in-house Perl scripts.

For each of the 456 ortholog groups, multiple alignments of protein sequences were performed using ClustalW2, and the corresponding coding-sequence alignments were obtained accordingly using PAL2NAL. For each species, all coding sequences from the alignments were concatenated to one supergene, based on which, the phylogenetic relationship of these ten species were reconstructed using the maximum likelihood method in PhyML [107] and a best-fit substitution model suggested by JModeltest 2 [108]. Based on the single-copy ortholog groups identified and the phylogenetic tree reconstructed, the divergence times were estimated using the mcmctree program in PAML. For prior settings in age estimation, the root constraint of the ten species (i.e., the divergence between Asteroideae and Cichorioideae) was set to 49.76-50.97 MYA, the divergence of Helenieae (H. autumnale) from other Heliantheae alliance species was set to 30.7-31.78 MYA, and the divergence of Heliantheae was set to 28.92-29.89 MYA as suggested by the estimation of Huang et al. (2016) [60].

\section{Evolutionary analyses}

To examine the type of genes that showed accelerated evolution among the Mikania species and also identify genes under positive selection, orthologous genes were identified using the bidirectional-best-hits method for the six species (i.e., $M$. micrantha, $M$. cordata, $M$. cordifolia, C. odorata, S. rebaudiana, and A. montana). The pairwise likelihood method in PAML was employed to calculate evolutionary parameters for each ortholog of the three Mikania species, including the total numbers of nonsynonymous (A) and synonymous (S) substitutions, 
$\mathrm{Ka}, \mathrm{Ks}$, and their ratio (i.e., $\mathrm{Ka} / \mathrm{Ks}$ ). After assigning GO annotations to these orthologs, the average Ka, Ks, and $\mathrm{Ka} / \mathrm{Ks}$ values for each $\mathrm{GO}$ categories were obtained. To evaluate the statistical significance that the evolutionary rates of a group of genes differ between two species pairs (e.g., M. micrantha-M. cordata vs. M. cordata-M. cordifolia), a $2 \times 2$ contingency table was built, with the four entries being the total $A$ and $S$ values in either of the two species pairs. Fisher's exact test was then applied to the table to test statistical significance that evolutionary rates differed between the two species pairs [70]. To evaluate the significance of the inequality in number of genes with higher $\mathrm{Ka} / \mathrm{Ks}$ in one species pair versus those in the other species pair, the two-tailed binomial test was used. To assess the significance that the two sets of $\mathrm{Ka} / \mathrm{Ks}$ values had distinct distributions, the nonparametric Wilcoxon signed-rank test was used. The statistic works were accomplished using custom perl scripts and $\mathrm{R}$ packages (for binomial test and Wilcoxon test) [109].

For lineage-specific analysis, values of $\mathrm{Ka}, \mathrm{Ks}$, and $\mathrm{Ka} / \mathrm{Ks}$ were estimated for each ortholog of the three Mikania species using the free-ratio model implemented in the codeml module of PAML, and median values were selected to represent the lineage-specific values since the median is more robust and less influenced by outliers than the mean. To detect candidate genes that have undergone positive selection in $M$. micrantha, the optimized branch-site model implemented in the codeml module of PAML was used, with M. micrantha as foreground branch and all other branches in the tree as background branches. A likelihood ratio test (LRT) was performed to assess the difference between the results of null and alternative models, and the LRT $P$-values were further tested using the FDR method with a conservative criterion of 0.05 to correct for multiple comparisons. GO categories with significantly higher representation of PSGs than background levels were detected using the Fisher's exact test in GOBU. The abundance of each PSG was measured with the normalizing statistic FPKM (fragments mapped per kilobase of exon per million reads mapped) calculated using RSEM [110].

\section{Additional files}

Additional file 1: Top-hit species categories of the non-redundant sequences of M. micrantha, M. cordata, and M. cordifolia assemblies. (PDF $18 \mathrm{~kb}$ )

Additional file 2: Length (a) and GC (b) distributions of the assembled unigenes of M. micrantha, M. cordata, and M. cordifolia. (PDF $202 \mathrm{~kb}$ )

Additional file 3: Assessment of per-base sequence accuracy of $M$. micrantha, M. cordata, and M. cordifolia unigenes. (a) Mapping depth distribution of assembled unigene sequences. Histogram shows the percentages of bases with certain ranges of coverage depth. (b) Identity distribution between assembled unigenes and their corresponding sequences from public databases. (PDF $132 \mathrm{~kb}$ )
Additional file 4: Downloaded nucleotide sequences from public databases and their alignment statistics. (PDF $117 \mathrm{~kb}$ )

Additional file 5: Sanger sequencing-derived sequences and their alignment statistics. (PDF $179 \mathrm{~kb}$ )

Additional file 6: Sequence comparison of M. micrantha, M. cordata, and M. cordifolia ortholog pairs. (PDF $35 \mathrm{~kb}$ )

Additional file 7: Similarity search and annotation of M. micrantha, $M$. cordata, and M. cordifolia unigenes. (a) Histogram plot of the data distribution based on search against multiple public databases. (b/c/d) Species/E-value/ similarity distributions of top hits for the unigenes based on BLAST search against NCBI non-redundant protein (NR) database. (PDF $414 \mathrm{~kb}$ )

Additional file 8: $\mathrm{GO}$ terms significantly enriched in M. micrantha compared with both M. cordata and M. cordifolia. Significance was tested using Fisher's exact test and control of false discovery rate (FDR) with $P$-value cutoff of 0.05 . (XLSX $37 \mathrm{~kb}$ )

Additional file 9: KEGG pathways with genes significantly differed between two species. (a) M. micrantha-M. cordata. (b) M. micrantha-M. cordifolia. (c) M. cordata-M. cordifolia. Significance was tested using Fisher's exact test and control of false discovery rate (FDR) with P-value cutoff of 0.05. (XLSX $31 \mathrm{~kb}$ )

Additional file 10: KOG classification for M. micrantha, M. cordata, and M. cordifolia unigenes. A total of 11,127, 11,497, and 29,854 unigenes, respectively, were grouped into 26 clusters of ortholog group terms. (PDF $74 \mathrm{~kb}$ )

Additional file 11: Number of differentially expressed genes (DEGs) under different dispersion values. (PDF $49 \mathrm{~kb}$ )

Additional file 12: List of genes that were up- and down-regulated in M. micrantha compared with both M. cordata and M. cordifolia. (XLSX $246 \mathrm{~kb}$ )

Additional file 13: $\mathrm{GO}$ categories over-represented in the list of up-regulated genes in M. micrantha. (XLSX $46 \mathrm{~kb}$ )

Additional file 14: Top 10\% GO categories displaying the highest $\mathrm{Ka} / \mathrm{Ks}$ ratios between two species. (a) M. micrantha-M. cordata. (b) M. micrantha-M. cordifolia. (c) M. cordata-M. cordifolia. (XLSX 19 kb)

Additional file 15: Identification of GO categories with accelerated evolution between invasive and non-invasive Mikania. (a) M. micrantha-M. cordata vs. M. cordata-M. cordifolia. (b) M. micrantha-M. cordifolia vs. M. cordata-M. cordifolia. (XLSX 36 kb)

Additional file 16: Distribution of branch-specific Ka/Ks for M. micrantha, M. cordata, and M. cordifolia. (PDF $41 \mathrm{~kb}$ )

Additional file 17: Positively selected genes identified in (a) M. micrantha, (b) M. cordata, and (c) M. cordifolia. (XLSX $39 \mathrm{~kb}$ )

Additional file 18: Functional categories overrepresented among genes under positive selection in M. micrantha. Significance was tested using Fisher's exact test and control of false discovery rate (FDR) with P-value cutoff of 0.05. (XLSX $22 \mathrm{~kb})$

\section{Abbreviations}

Cl: Credibility interval; CPM: Count per million; DEG: Differentially expressed gene; EC: Enzyme commission; FDR: False discovery rate; FPKM: Fragments per kilobase of exon region in a given gene per million mapped fragments; GO: Gene ontology; Ka: Nonsynonymous substitution rate; Ka/Ks: Ratio of nonsynonymous to synonymous substitution rates; KEGG: Kyoto Encyclopedia of Genes and Genomes; KOG: Eukaryotic Orthologous Group; Ks: Synonymous substation rate; LRT: Likelihood ratio test; MYA: Million years ago; NR: NCBI non-redundant protein; NT: NCBI non-redundant nucleotide; PSG: Positively selected gene; RNA-seq: RNA-sequencing

\section{Acknowledgements}

We thank Profs. Shong Huang, Suhua Shi and Xuejun Ge for sampling and insightful comments.

\section{Funding}

National Natural Science Foundation of China (Grant Nos. 41776166 and 31700178), the Natural Science Foundation of Guangdong Province (Grant No. 2015A030313136 and 2017A030313159), Special Fund for Science and Technology Development of Guangdong Province (2017A030303014), the 
Science Foundation of the State Key Laboratory of Biocontrol (32-2017-A30), the Science and Technology Program of Guangzhou (Grant No. 201707020035) and the Chang Hungta Science Foundation of Sun Yat-sen University.

\section{Availability of data and materials}

The RNA-seq datasets generated by using Illumina-Solexa platform are available from the NCBI Sequence Read Archive database (SRA; http://www.ncbi.nlm.nih. gov/sra) under experiment number accession SRX3520663, SRX3520664, and SRX3520665.

\section{Authors' contributions}

$\mathrm{YLH}$ and $\mathrm{YL}$ designed the study. $\mathrm{YL}, \mathrm{PCL}, \mathrm{BHH}$ and $\mathrm{YLH}$ collected materials. WXG, YL, WXL, CML and XGS performed experiments. WXG analyzed and interpreted the data. WXG, WLN, YLH wrote the manuscript. All authors read and approved the final manuscript.

\section{Ethics approval and consent to participate} Not applicable.

\section{Competing interests}

The authors declare that they have no competing interests.

\section{Publisher's Note}

Springer Nature remains neutral with regard to jurisdictional claims in published maps and institutional affiliations.

\section{Author details}

'State Key Laboratory of Biocontrol and Guangdong Provincial Key Laboratory of Plant Resources, School of Life Sciences, Sun Yat-sen University, 135 Xingang West Road, 510275 Guangzhou, Guangdong, People's Republic of China. ${ }^{2}$ Department of Life Science, National Taiwan Normal University, Taipei, Taiwan

\section{Received: 2 January 2018 Accepted: 11 May 2018}

\section{Published online: 24 May 2018}

\section{References}

1. Wilcove DS, Rothstein D, Dubow J, Phillip A, Losos E. Quantifying threats to imperiled species in the United States. Bioscience. 1998;48:607-15. https:// doi.org/10.2307/1313420

2. Pimentel D, Lach L, Zuniga R, Morrison D. Environmental and economic costs of nonindigenous species in the United States. Bioscience. 2000;50:53-65. https://doi.org/10.1641/0006-3568(2000)050[0053:EAECON]2.3.CO;2.

3. Sakai AK, Allendorf FW, Holt JS, Lodge DM, Molofsky J, With KA, et al. The population biology of invasive species. Annu Rev Ecol Syst. 2001;32:305-32. https://doi.org/10.1146/annurev.ecolsys.32.081501.114037.

4. Bossdorf O, Auge H, Lafuma L, Rogers WE, Siemann E, Prati D. Phenotypic and genetic differentiation between native and introduced plant populations. Oecologia. 2005;144:1-11. https://doi.org/10.1007/s00442-005-0070-z.

5. Hu L, Li M, Wei P. Salt tolerance of the invasive vine Mikania micrantha Kunth. Ecol Environ Sci. 2014;23(1):7-15.

6. Sala OE, Chapin FS, Armesto JJ, Berlow E, Bloomfield J, Dirzo R, et al. Global biodiversity scenarios for the year 2100. Science. 2000;287:1770-4 https://doi.org/10.1126/science.287.5459.1770.

7. Levine J, Vila M, D'Antonio CM, Dukes JS, Grigulis K, Lavorel S. Mechanisms underlying the impact of exotic plant invasions. Proc R Soc Lond B. 2003;270:775-81

8. Elton CS. The ecology of invasion by animals and plants. London: Methuen; 1958. https://doi.org/10.1210/endo-63-4-464

9. Deng X, Ye W, Feng H, Yang Q, Cao H, Xu K, et al. Gas exchange characteristics of the invasive species Mikania micrantha and its indigenous congener M. cordata (Asteraceae) in South China. Bot Bull Acad Sin. 2004;45:213-20.

10. Daehler CC. Variation in self-fertility and the reproductive advantage of selffertility for an invading plant (Spartina alterniflora). Evol Ecol. 1998;12:553-68. https://doi.org/10.1023/A:1006556709662.

11. Callaway RM, Aschehoug ET. Invasive plants versus their new and old neighbors: a mechanism for exotic invasion. Science. 2000;290:521-3. https://doi.org/10.1126/science.290.5491.521.

12. Hertling UM, Lubke RA. Assessing the potential for biological invasion-the case of Ammophila arenarian. S Afr J Sci. 2000;96:520-7.
13. Zhang LY, Ye WH, Cao HL, Feng HL. Mikania micrantha H. B. K. In China-an overview. Weed Res. 2004;44(1):42-9. https://doi.org/10.1111/j.1365-3180. 2003.00371.x.

14. Wu JR, Peng SL. Allelopathy: "novel weapons" of exotic invasive plants. Acta Ecol Sin. 2005;25:3093-7.

15. Song L, Peng C, Peng S. Comparison of leaf construction costs between three invasive species and three native species in south China. biodivsci. 2009;17(4):378-84.

16. Herraiz FJ, Blanca J, Ziarsolo P, Plazas M, Anderson GJ, Prohens J, Vilanova S. The first de novo, transcriptome of pepino ( Solanum muricatum ): assembly, comprehensive analysis and comparison with the closely related species S. caripense, potato and tomato. BMC Genomics. 2016;17(1):321.

17. PalmaSilva C, Ferro M, Bacci M, TurchettoZolet AC. De novo assembly and characterization of leaf and floral transcriptomes of the hybridizing bromeliad species (Pitcairnia spp.) adapted to Neotropical inselbergs. Mol Ecol Resour. 2016;16(4):1012-22. https://doi.org/10.1111/1755-0998.12504.

18. Zhou T, Chen C, Wei Y, Chang Y, Bai G, Li Z, Kanwal N, Zhao G. Comparative transcriptome and chloroplast genome analyses of two related Dipteronia species. Front Plant Sci. 2016;7:1512. https://doi.org/10.3389/fpls.2016.01512.

19. Schierenbeck KA, Marshall JD. Seasonal and diurnal patterns of photosynthetic gas exchange for Lonicera Sempervirens and L. Japonica (Caprifoliaceae). Am J Bot. 1993;80(11):1292-9. https://doi.org/10.1002/j. 1537-2197.1993.tb15367.x.

20. Mack RN. Predicting the identity and fate of plant invaders: emergent and emerging approaches. Biol Convers. 1996;78:107-21.

21. Holm LG, Plucknett DL, Pancho JV, Herberge JP. The World's worst weeds: distribution and biology. Honolulu: University Press of Hawaii; 1977.

22. Waterhouse DF. Biological control of weeds: southeast Asian prospects. Australian Centre for International Agricultural Research: Canberra; 1994. https://doi.org/10.1111/j.1365-2672.1994.tb04393.x.

23. Li WH, Zhang CB, Jiang $H$, Xin GR, Yang ZY. Changes in soil microbial community associated with invasion of the exotic weed, Mikania micrantha H. B K Plant Soil. 2006;281(1/2):309-24.

24. Xu G, Shen S, Zhang F. Adaptability and reproductive characteristics of Mikania micrantha H. B. K under different habitats. Ecol Environ Sci. 2014; 23(8):1258-64.

25. Zan QJ, Wang YJ, Wang BS, Liao WB, Li MG. The distribution and harm of the exotic weed Mikania micrantha. Chin J Ecol. 2000;19:58-61.

26. Abraham M, Abraham CT. Mile-a-minute weed effects on crop plants. Indian Fmg. 2005;55:9-10.

27. Li WH, Zhang CB, Gao GJ, Zan QJ, Yang ZY. Relationship between Mikania micrantha invasion and soil microbial biomass, respiration and functional diversity. Plant Soil. 2007;296:197-207. https://doi.org/10.1007/s11104-0079310-9.

28. Zhang F, Li T, Xu G, Wu D, Zhang Y. Comparative analysis of growth types and reproductive characteristics of Mikania micrantha. Chin Bull Bot. 2011:46(1):59-66.

29. Shen $S, X u G$, Clements DR, Jin G, Chen A, Zhang F, et al. Suppression of the invasive plant mile-a-minute (Mikania micrantha) by local crop sweet potato (Ipomoea batatas) by means of higher growth rate and competition for soil nutrients. BMC Ecol. 2015;15:1. https://doi.org/10.1186/s12898-0140033-5.

30. Holmes WC. Revision of the old world Mikania (Compositae). Bot Jahrb. 1982;103(2):211-46.

31. King RM, Robinson $\mathrm{H}$. The genera of the Eupatoriae (Asteraceae). Monogr Syst Bot Missouri Bot Gard. 1987;22:1-581.

32. Holmes WC. A review preparatory to an infrageneric classification of Mikania (tribe: Eupatoriae). In: Hind DJN, Jeffrey C, Pope GV, editors. Advances in Compositae systematics 1. Kew: The Royal Botanic Gardens; 1995. p. 239-54.

33. Wang B, Liao W, Zan Q, Li M, Zhou X, Gao S. The spreads of Mikania micrantha in China. Acta Sci Natur Univ Sunyatseni. 2003;42(4):47-54.

34. Kong GH, Wu QG, Hu QM. Appearing of exotic weed Mikania micrantha $\mathrm{H}$. B K in China J Trop Subtrop Bot. 2000;8:27.

35. Wang BS, Liao WB, Miao RH. Revision of Mikania from China and the key of four relative species. Acta Sci Natur Univ Sunyatseni. 2001;40:72-5.

36. Willis $\mathrm{M}$, Zerbe $\mathrm{S}$, Kuo YL. Distribution and ecological range of the alien plant species Mikania micrantha Kunth (Asteraceae) in Taiwan. J Ecol Environ. 2008;31(4):277-90. https://doi.org/10.5141/JEFB.2008.31.4.277.

37. Li M, Lu B, Guo Q, Zan Q, Wei P, Jiang L, et al. Evaluation of the controlling methods and strategies for Mikania micrantha H. B K Acta Ecol Sin. 2012; 32(10):3240-51. 
38. Jiang L, Zhang Y, Guo Q, Liu Y, Li C. Cytology of Mikania cordata (Asteraceae), a Native Plant in China; 2017. https:/doi.org/10.1 1931/guihaia.gxzw201703023.

39. Swamy PS, Ramakrishnan PS. Weed potential of Mikania micrantha H.B.K. And its control in fallows after shifting agriculture (Jhum) in north-East India. Agric Ecosyst Environ. 1987;18:195-204. https://doi.org/10.1016/01678809(87)90083-1.

40. Li MG, Zhang WY, Wang BS, Zhang JL, Zan QJ, Wang YJ. A preliminary study on the seed germination in Mikania micrantha. Acta Sci Natur Univ Sunyatseni. 2002;41(6):57-9.

41. Feng $\mathrm{HL}$, Cao HL, Liang XD, Zhou X, Ye WH. The distribution and harmful effect of Mikania micrantha in Guangdong. J Trop Subtrop Bot. 2002;10:263-70.

42. Shao H, Peng SL, Liu YX, Zhang C, Xiang YC. The biological control and the natural enemy of Mikania micrantha H.B.K.'s in China. Ecol Sci. 2002;21:33-6.

43. Yang $\mathrm{QH}$, Feng $\mathrm{HL}$, Ye WH, Cao HL, Deng X, Xu KY. An investigation of the effects of environmental factors on the flowering and seed setting of Mikania micrantha H.B.K (Compositae). J Trop Subtrop Bot. 2003;11:123-6.

44. Bakir M, Facey PC, Hassan I, Mulder WH, Porter RB. Mikanolide from Jamaican Mikania micrantha. Acta Crystallogr C. 2004;60:798-800.

45. Ismail BS, Chong TV. Effects of aqueous extracts and decomposition of Mikania micrantha H. B. K. Debris on selected agronomic crops. Weed Biol and Manag. 2002;2:31-8. https://doi.org/10.1046/j.1445-6664.2002.00045.x.

46. Du F, Yang Y, Li J, Yi W. A review of Mikania and the impact of M. micrantha (Asteraceae) in Yunnan. Acta Bot Yunnanica. 2006;28(5):505-8.

47. Deng X. Morphological and physiological plasticity responding to different light environments of the invasive plant, Mikania micrantha H.B.Kunth. Ecol Environ Sci. 2010;19(5):1170-5.

48. Wang T, Wang Z, Chen G, Wang C, Su Y. Invasive chloroplast population genetics of Mikania micrantha in China: no local adaptation and negative correlation between diversity and geographic distance. Front Plant Sci. 2016;7:1426. https://doi.org/10.3389/fpls.2016.01426.

49. Yang $M$, He Z, Huang $Y, L u L$, Yan $Y$, Hong $L$, et al. The emergence of the hyper-invasive vine, Mikania micrantha (Asteraceae), via admixture and founder events inferred from population transcriptomics. Mol Ecol. 2017; 26(13):3405-23. https://doi.org/10.1111/mec.14124.

50. Baker MG, Brown ND, Press MC. Photosynthetic characteristics of dipterocarp seedlings in different tropical rain forest light environments: a basis for niche-partitioning? Oecologia. 1997;112:453-63.

51. Huang ZL, Cao HL, Liang XD, Ye WH, Feng HL, Cai CX. The growth and damaging effect of Mikania micrantha in different habitats. J Trop Subtrop Bot. 2000;8:131-8.

52. Wu H, Zeng $\mathrm{H}$, Zan Q. Considerations on some issues in research of the invasion mechanisms of the exotic weed Mikania micrantha. J Trop Subtrop Bot. 2010;18(1):101-8.

53. Ellison CA, Evans HC, Djeddour DH, Thomas SE. Biology and host range of the rust fungus Puccinia spegazzinii: a new classical biological control agent for the invasive, alien weed Mikania micrantha in Asia. Biol Control. 2008;45: 133-45. https://doi.org/10.1016/j.biocontrol.2007.12.001.

54. Wang T, Chen G, Zan Q, Wang C, Su Y. AFLP genome scan to detect genetic structure and candidate loci under selection for local adaptation of the invasive weed Mikania micrantha. PLoS One. 2012;7(7):e41310. https:// doi.org/10.1371/journal.pone.0041310

55. Huang $Y$, Fang $L$, Lu L, Yan Y, Chen $S$, Hu L, et al. Transcriptome analysis of an invasive weed Mikania micrantha. Biol Plant. 2012:56:111-6. https://doi. org/10.1007/s10535-012-0024-3.

56. Hong L, Liu M, Shen H, Ye W, Cao H. Reproductive allocation of biomass in Mikania micrantha populations from two habitats. Plant Sci J. 2010;28(5):598-605.

57. Holmes WC. Mikania (Compositae) of the United States. Sida. 1981;9:147-58.

58. Holmes WC. The genus Mikania (Compositae: Eupatorieae) in the greater Antilles. Botanical Research Institute of Texas: Fort Worth; 1993.

59. Funk VA, Susanna A, Stuessy TF, Robinson H. Classification of Compositae. In: Funk VA, Susanna A, Stuessy TF, Bayer RJ, editors. Systematics, evolution, and biogeography of Compositae. Vienna: International Association for Plant Taxonomy; 2009. p. 171-92.

60. Huang C, Zhang C, Liu M, Hu Y, Gao T, Qi J, et al. Multiple polyploidization events across Asteraceae with two nested events in the early history revealed by nuclear phylogenomics. Mol Biol Evol. 2016;33(11):2820-35. https:/doi.org/ 10.1093/molbev/msw157.

61. Molnar P. Mio-Pliocene growth of the Tibetan plateau and evolution of east Asian climate. Palaeontol Electron. 2005;8:2A-23P.

62. Bruch AA, Uhl D, Mosbrugger V. Miocene climate in Europe - patterns and evolution: a first synthesis of NECLIME. Palaeogeogr Palaeocl. 2007;253:1-7.
63. Xing Y, Utescher T, Jacques FMB, Su T, Liu Y, Huang Y, et al. Paleoclimatic estimation reveals a weak winter monsoon in southwestern China during the late Miocene: evidence from plant macrofossils. Palaeogeogr Palaeocl. 2012:358-360:19-26.

64. Behrensmeyer AK, Damuth JD, DiMichele WA, Potts R, Sues HD, Scott L. Terrestrial ecosystems through time: evolutionary paleoecology of terrestrial plants and animals. Chicago: The University of Chicago Press; 1992.

65. Robinson MD, McCarthy DJ, Smyth GK. EDGER: a Bioconductor package for differential expression analysis of digital gene expression data. Bioinformatics. 2010;26:139-40.

66. Rieseberg $L H$, Blackman BK. Speciation genes in plants. Ann Bot. 2010; 106(3):439-55. https://doi.org/10.1093/aob/mcq126.

67. Siol M, Wright SI, Barrett SC. The population genomics of plant adaptation. New Phytol. 2010;188(2):313-32. https://doi.org/10.1111/j.1469-8137.2010. 03401.X.

68. Yang Y, Yang S, Li J, Deng Y, Zhang Z, Xu S, et al. Transcriptome analysis of the Holly mangrove Acanthus ilicifolius and its terrestrial relative, Acanthus leucostachyus, provides insights into adaptation to intertidal zones. BMC Genomics. 2015;16:605.

69. Castillo-Davis Cl, Kondrashov FA, Hartl DL, Kulathinal RJ. The functional genomic distribution of protein divergence in two animal phyla: coevolution, genomic conflict, and constraint. Genome Res. 2004;14:802-11. https://doi.org/10.1101/gr.2195604

70. Dorus S, Vallender EJ, Evans PD, Anderson JR, Gilbert SL, Mahowald M. Accelerated evolution of nervous system genes in the origin of Homo sapiens. Cell. 2004;1 19:1027-40. https://doi.org/10.1016/..cell.2004.11.040

71. Croenen MAM, Archibald AL, Uenishi H, Tuggle CK, Takeuchi Y, Rothschild $M F$, et al. Analyses of pig genomes provide insight into porcine demography and evolution. Nature. 2012;491:393-8.

72. Qiu Q, Zhang G, Ma T, Qian W, Wang J, Ye Z, et al. The yak genome and adaptation to life at high altitude. Nature Genet. 2012;44(8):946. https://doi. org/10.1038/ng.2343.

73. Yang ZH. PAML 4: phylogenetic analysis by maximum likelihood. Mol Biol Evol. 2007;24:1586-91. https://doi.org/10.1093/molbev/msm088.

74. Letcher SG, Chazdon RL. Lianas and self-supporting plants during tropical forest succession. Forest Ecol Manag. 2009;257:2150-6. https://doi.org/10. 1016/j.foreco.2009.02.028.

75. Kami C, Lorrain S, Hornitschek P, Fankhauser C. Chapter two-light-regulated plant growth and development. Curr Top Dev Biol. 2010;91:29-66.

76. Velanis $\mathrm{CN}$, Herzyk P, Jenkins $\mathrm{Gl}$. Regulation of transcription by the Arabidopsis UVR8 photoreceptor involves a specific histone modification. Plant Mol Biol. 2016;92:425-43. https://doi.org/10.1007/s11103-016-0522-3.

77. Hurlbert SH. A gentle depilation of the niche: Dicean resource sets in resource hyperspace. Evol Theor. 1981;5:117-84.

78. Wen D, Ye W, Feng H, Cai C. Comparison of basic photosynthetic characteristics between exotic invader weed Mikania micrantha and its companion species. J Trop Subtrop Bot. 2000;8(2):139-46.

79. Ohta N, Sato N, Ueda K, Kuroiwa T. Analysis of a plastid gene cluster reveals a close relationship between Cyanidioschyzon and Cyanidium. J Plant Res. 1997;110(2):235-45. https://doi.org/10.1007/BF02509312.

80. Hemmingsen SM, Ellis RJ. Purification and properties of Ribulosebisphosphate carboxylase large subunit binding protein. Plant Physiol. 1986;80(1):269-76. https://doi.org/10.1104/pp.80.1.269.

81. Ishikawa A, Tanaka H, Nakai M, Asahi T. Deletion of a chaperonin 60 beta gene leads to cell death in the Arabidopsis lesion initiation 1 mutant. Plant Cell Physiol. 2003;44(3):255. https://doi.org/10.1093/pcp/pcg031.

82. Doan DNP, Rudi $\mathrm{H}$, Olsen O. The allosterically unregulated isoform of ADP-glucose Pyrophosphorylase from barley endosperm is the most likely source of ADP-glucose incorporated into endosperm starch. Plant Physiol. 1999;121(3):965-75. https://doi.org/10.1104/pp.121.3.965.

83. Hejazi M, Mahlow S, Fettke J. The glucan phosphorylation mediated by a-glucan, water dikinase (GWD) is also essential in the light phase for a functional transitory starch turn-over. Plant Signal Behav. 2014;9(7):e28892. https://doi.org/10.4161/psb.28892.

84. Deng X. Progress on agricultural alien weed Mikania micrantha H. B Kunth Guangdong Agric Sci. 2010;37(9):196-8.

85. Kim J, Huang WP, Klionsky DJ. Membrane recruitment of Aut7p in the autophagy and cytoplasm to vacuole targeting pathways requires Aut1p, Aut2p, and the autophagy conjugation complex. J Cell Biol. 2001;152(1):51-64. https://doi.org/10.1083/jcb.152.1.51. 
86. Kim DH, Sarbassov DD, Ali SM, Latek RR, Guntur KV, Erdjument-Bromage H, Tempst P, Sabatini DM. Gbetal, a positive regulator of the rapamycinsensitive pathway required for the nutrient-sensitive interaction between raptor and mtor. Mol Cell. 2003;11(4):895-904. https://doi.org/10.1016/ S1097-2765(03)00114-X.

87. Salem MA, Li Y, Wiszniewski A, Giavalisco P. Regulatory-associated protein of tor (raptor) alters the hormonal and metabolic composition of Arabidopsis seeds controlling seed morphology, viability and germination potential. Plant J. 2017;92(4):525-45. https://doi.org/10.1111/tpj.13667.

88. Müller CW, Schlauderer GJ, Reinstein J, Schulz GE. Adenylate kinase motions during catalysis: an energetic counterweight balancing substrate binding. Structure. 1996;4(2):147. https://doi.org/10.1016/S0969-2126(96)00018-4.

89. Mato E, Barceló-Batllori S, Orera I, Selva L, Corra M, González C, Bell O, Lerma E, Moral A, Pérez JI, de Leiva A. The proteomic 2D-DIGE approach reveals the protein voltage-dependent anion channel 2 as a potential therapeutic target in epithelial thyroid tumours. Mol Cell Endocrinol. 2015;404(C):37-45.

90. Nakamura H, Xue YL, Miyakawa T, Hou F, Qin HM, Fukui K, Shi X, Ito E, Ito S, Park SH, Miyauchi Y, Asano A, Totsuka N, Ueda T, Tanokura M, Asami T. Molecular mechanism of strigolactone perception by dwarf14. Nat Commun. 2013;48(4):2613.

91. Rigó G, Ayaydin F, Tietz O, Zsigmond L, Kovács H, Páy A, Salchert K, Darula Z, Medzihradszky KF, Szabados L, Palme K, Koncz C, Cséplo A. Inactivation of plasma membrane-localized CDPK-RELATED KINASE5 decelerates PIN2 exocytosis and root gravitropic response in Arabidopsis. Plant Cell. 2013; 25(5):1592-608. https://doi.org/10.1105/tpc.113.110452.

92. Han W, Christen P. Interdomain communication in the molecular chaperone DnaK. Biochem J. 2003;369(3):627-34. https://doi.org/10.1042/bj20020943.

93. Russell BL, Rathinasabapathi B, Hanson AD. Osmotic stress induces expression of choline monooxygenase in sugar beet and Amaranth. Plant Physiol. 1998;116(2):859. https://doi.org/10.1104/pp.116.2.859.

94. Fu X, Deng S, Su G, Zeng Q, Shi S. Isolating high-quality RNA from mangroves without liquid nitrogen. Plant Mol Biol Rep. 2004;22(2):197. https://doi.org/10. 1007/BF02772728.

95. Andrews S. FastQC: A quality control tool for high throughput sequence data. 2010. Available online at: http://www.bioinformatics.babraham.ac.uk/ projects/fastqc/

96. Grabherr MG, Haas BJ, Yassour M, Levin JZ, Thompson DA, Amit I, et al. Fulllength transcriptome assembly from RNA-Seq data without a reference genome. Nat Biotechnol. 2011;29:644-52. https://doi.org/10.1038/nbt.1883.

97. Li H, Durbin R. Fast and accurate short read alignment with burrowswheeler transform. Bioinformatics. 2009;25(14):1754-60. https://doi.org/10. 1093/bioinformatics/btp324.

98. Li H, Handsaker B, Wysoker A, Fennell T, Ruan J, Homer N, Marth G, Abecasis $\mathrm{G}$, Durbin R. 1000 genome project data processing subgroup. The sequence alignment/map (SAM) format and SAMtools. Bioinformatics. 2009;25:2078-9. https://doi.org/10.1093/bioinformatics/btp352.

99. Kent WJ. BLAT-the BLAST-like alignment tool. Genome Res. 2002;12(4):656-64. https:/doi.org/10.1101/gr.229202.

100. Conesa A, Gotz S, Garcia-Gomez JM, Terol J, Talon M, Robles M. Blast2GO: a universal tool for annotation, visualization and analysis in functional genomics research. Bioinformatics. 2005;21:3674-6. https://doi.org/10.1093/ bioinformatics/bti610.

101. Lin WD, Chen YC, Ho JM, Hsiao CD. GOBU: toward an integration interface for biological objects. J Assoc Inf Sci TecH. 2006;22:19-29.

102. Langmead B, Trapnell C, Pop M, Salzberg SL. Ultrafast and memory-efficient alignment of short DNA sequences to the human genome. Genome Biol. 2009;10:R25. https://doi.org/10.1186/gb-2009-10-3-r25.

103. Anders S, Pyl PT, Huber W. HTSeq - a Python framework to work with high-throughput sequencing data. Bioinformatics. 2015;31:166-9. https://doi. org/10.1093/bioinformatics/btu638.

104. Larkin MA, Blackshields G, Brown NP, Chenna R, Mcgettigan PA, Mcwilliam $\mathrm{H}$, et al. Clustal W and clustal X version 2.0. Bioinformatics. 2007;23:2947-8. https://doi.org/10.1093/bioinformatics/btm404.

105. Suyama M, Torrents D, Bork P. PAL2NAL: robust conversion of protein sequence alignments into the corresponding codon alignments. Nucleic Acids Res. 2006;34:W609-12. https://doi.org/10.1093/nar/gkl315.

106. Li L, Stoeckert CJ, Roos DS. OrthoMCL: identification of ortholog groups for eukaryotic genomes. Genome Res. 2003;13:2178-89. https://doi.org/10.1101/ gr.1224503.

107. Guindon S, Dufayard JF, Lefort V, Anisimova M, Hordijk W, Gascuel O. New algorithms and methods to estimate maximum-likelihood phylogenies: assessing the performance of PhyML 3.0. Syst Biol. 2010;59:307-21. https:// doi.org/10.1093/sysbio/syq010.

108. Darriba D, Taboada GL, Doallo R, Posada D. jModelTest 2: more models, new heuristics and parallel computing. Nat Methods. 2012;9(8):772. https://doi.org/10.1038/nmeth.2109.

109. R Development Core Team. R: a language and environment for statistical computing. Vienna: R Foundation for Statistical Computing; 2013. https:// www.r-project.org/

110. Li B, Dewey C. RSEM: accurate transcript quantification from RNA-Seq data with or without a reference genome. BMC Bioinformatics. 2011;12:323. https://doi.org/10.1186/1471-2105-12-323.

\section{Ready to submit your research? Choose BMC and benefit from:}

- fast, convenient online submission

- thorough peer review by experienced researchers in your field

- rapid publication on acceptance

- support for research data, including large and complex data types

- gold Open Access which fosters wider collaboration and increased citations

- maximum visibility for your research: over $100 \mathrm{M}$ website views per year

At BMC, research is always in progress.

Learn more biomedcentral.com/submissions 